\title{
Amphoteric gellan gum-based terpolymer-montmorillonite composite: synthesis, swelling, and dye adsorption studies
}

\author{
Sirajo Abubakar Zauro ${ }^{1}$ B. Vishalakshi ${ }^{1}$
}

Received: 5 October 2016/ Accepted: 14 June 2017/Published online: 6 July 2017

(C) The Author(s) 2017. This article is an open access publication

\begin{abstract}
A terpolymer gel, Gellan gum-graft-poly(2acrylamido-2-methyl-1-propanesulfonic acid-co-dimethylaminopropyl methacrylamide) and its composite with the clay, Montmorillonite, was prepared by free-radical polymerization and crosslinking reactions in solution. The terpolymer gel and the clay composite were characterized using FTIR, TGA, SEM, and X-ray diffraction techniques. Swelling studies were carried out in different $\mathrm{pH}$ and salt solutions. The gel showed maximum swelling capacity in alkaline medium, while the composite showed higher swelling in neutral medium. The swelling of the gel and the composite followed second kinetics model and water transport is found to be a less Fickian diffusion process. The terpolymer gel and the composite were evaluated for the adsorption of rhodamine $\mathrm{B}(\mathrm{RhB})$ and chromotrope $2 \mathrm{R}$ (C2R) dyes. Rhodamine $\mathrm{B}$ is found to be adsorbed to a higher extent than chromotrope $2 \mathrm{R}$ and the adsorption isotherm studies suggested that adsorption of both $\mathrm{RhB}$ and $\mathrm{C} 2 \mathrm{R}$ on the terpolymer gel was best explained by Langmuir model, while the adsorption on the Composite fitted best into Freundlich model. Similarly, the adsorption kinetics data for both $\mathrm{RhB}$ and $\mathrm{C} 2 \mathrm{R}$ dyes followed the second-order kinetics.
\end{abstract}

Keywords Gellan gum · 2-Acrylamido-2-methyl-1propanesulfonic acid · Dimethylaminopropyl methacrylamide $\cdot$ Montmorillonite $\cdot$ Swelling . Dye adsorption

\section{B. Vishalakshi}

vishalakshi2009@yahoo.com

1 Department of Post-Graduate Studies and Research in Chemistry, Mangalore University, Mangalagangothri, Dakshina Kannada, Mangalore, Karnataka 574199, India

\section{Introduction}

The increasing demand for manufactured products worldwide and the use of synthetic dyes in various industries such as textile, leather, paper, rubber, plastic, cosmetic, etc. led to the proportionate release of a large quantity of effluent into the environment. In addition, this effluent contained non-biodegradable toxic and carcinogenic dye substances into the environment [1-5]. Rhodamine B $(\mathrm{RhB})$ and chromotrope $2 \mathrm{R}(\mathrm{C} 2 \mathrm{R})$ are synthetic dyes that are commonly used in leather, textile, and paper industries and cause various health hazards $[6,7]$.

The composites and nanocomposite of polymer-clay have been gaining increase attention by researchers globally due to the hybrid properties which they exhibit when compared with either the polymer or clay separately [8]. A wide range of polymer-clay composite/nanocomposite has been produced and used for a variety of applications such as water treatment $[5,8]$, dye adsorption [2, 9-11], etc.

Several physical and chemical methods like chemical precipitation, ion exchange, membrane separation, chemical reduction, chemical oxidation, advanced oxidation processes (AOPs), etc. [12] have been employed in the removal of toxic substances from the environment. However, these methods are ineffective in removing most of the dyes molecules and are time-consuming, not cost-effective, and sometimes generate large amount of sludge that are toxic to the biotic organisms in the environment. Hence, adsorption using biopolymer-based composites has been described as one of the effective and promising techniques for removal of pollutants due to its simplicity, inexpensiveness, etc. [13-18].

Several biopolymer-based hydrogels such as Gum gatti [19], Gur gum [14], Kappa carrageenan [20-22], chitosan 
[23], and Guaran [24] were studied as adsorbents for the removal of dyes from aqueous solution. Casey and Wilson [25] reported the adsorption of Methylene blue (MB) dye on Chitosan-PVA composite films and direct relationship between film composition (Chitosan-PVA) with solution $\mathrm{pH}$ and the uptake of MB were observed. Similarly, Datskevich et al. [26] synthesized cationic starch and sodium alginate-based composite and studied the adsorption of Methyl orange and MB under different conditions. The adsorption of congo red on Chitosan/Montmorillonite composite has been studied by Wang and Wang [1]. Vasugi and Girija [4] reported the adsorption of reactive blue dye on hydroxyapatite-alginate composite.

The composite materials consisting of clay and a biopolymer are very effective in removal of dyes due to the availability of numerous functional groups on the biopolymer and the clay for binding with the dye molecules, rendering the materials useful as adsorbents.

The aim of the present study is to obtain a functional composite hydrogel consisting of clay, a biopolymer, and a synthetic polymer to be evaluated as an adsorbent for dyes. This has been achieved by polymerizing AMPS, DMAPMAm, and MBA in the presence of gellan gum and montmorillonite (MMT) clay in water and its effectiveness as an adsorbent for removal of dyes has been studied using chromotrope $2 \mathrm{R}$ and rhodamine $\mathrm{B}$ as model ionic dyes.

\section{Materials and methods}

\section{Materials}

Gellan gum (GG) was purchased from Sigma-Aldrich Chemicals Pvt Ltd., Bangalore, India. 2-Acrylamidomethyl-2-propane sulfonic acid (AMPS), dimethylaminopropyl methacrylamide (DMAPMAm), N, $\mathrm{N}$-methylene-bis-acrylamide (MBA), and montmorillonite (MMT) were obtained from Sigma-Aldrich Chemie, $\mathrm{GmbH}$, Germany. Ammonium peroxodisulphate (APS) was obtained from Spectro Chem Pvt. Ltd., Mumbai, India. Rhodamine B (RhB) was obtained from s.d. Fine Chemical Limited, Mumbai, India. Chromotrope 2R (C2R) was purchased from Loba Chemie Limited Mumbai, India. Acetone was obtained from Nice Chemicals Pvt Ltd., Kerala, India. Methanol was obtained from Himedia Laboratories Pvt Ltd., Mumbai, India. $\mathrm{NaCl}, \mathrm{KCl}, \mathrm{FeCl}_{3}$, $\mathrm{CaCl}_{2}$, and $\mathrm{Na}_{2} \mathrm{SO}_{4}$ were obtained from Merck Ltd., Mumbai, India. DMAPMAm was purified by passing through column containing alumina gel before use. All other reagents were used as received. Distilled water was used throughout the experiments.

\section{Methods}

Synthesis of GG-g-AMPS

GG-g-AMPS was prepared via free-radical polymerization process as follows: $0.15 \mathrm{~g}$ GG was dissolved in distilled and stirred overnight. To the resultant solution, varying amounts $(0.1-0.30 \mathrm{~g})$ of AMPS were added followed by APS (0.05) under continues stirring. The temperature was raised to $40{ }^{\circ} \mathrm{C}$ under continues stirring for $2 \mathrm{~h}$. The gel was precipitated with acetone and washed with methanol several times, and dried in an oven at $50{ }^{\circ} \mathrm{C}$ for $24 \mathrm{~h}$.

\section{Synthesis of GG-g-poly(AMPS-co-DMAPMAm)}

The graft copolymer GG-g-poly(AMPS-co-DMAPMAm) gel was synthesized based on the established methods reported by Nie et al. [27] with a little modification as follows: a known amount of GG $(0.1 \mathrm{~g})$ was dissolved in distilled water and stirred overnight at room temperature. A specified amount of AMPS (0.1-0.30 g) and DMAPMAm $(0.15-0.50 \mathrm{~g})$ were added to the above solution. To the mixture above, APS $(0.05 \mathrm{~g})$ and MBA $(0.05 \mathrm{~g})$ were added and stirred by raising the temperature to $60{ }^{\circ} \mathrm{C}$ slowly for $4 \mathrm{~h}$ maintaining the temperature at $60{ }^{\circ} \mathrm{C}$ until a gel-like solution was formed. It was then allowed to cool for an hour to complete the polymerization and added to excess acetone to remove un-reacted components. The gels obtained were then washed with $50 \%$ ethanol and placed in a hot oven at $50{ }^{\circ} \mathrm{C}$ until constant weight was obtained. The GG-g-poly(AMPS-co-DMAPMAm) gel formation was optimized. The percentage yield and grafting percentage (GP) were calculated by the following equation:

$\%$ Yield $=\frac{\text { Experimental yield }}{\text { Theoretical yield }} \times 100$,

$\mathrm{GP}(\%)=\frac{\left(w_{1}-w_{\mathrm{o}}\right)}{w_{\mathrm{o}}} \times 100$,

where $w_{0}$ and $w_{1}$ are the weight of grafted gels and monomers, respectively.

\section{Synthesis of GG-g-poly(AMPS-co-DMAPMAm)/MMT}

The GG-g-poly(AMPS-co-DMAPMAm)/MMT composite hydrogel was made following the same procedure as in 2.2.2 with the addition of MMT (0.01-0.03 g) after adding DMAPMA under continuous stirring slowly during $1 \mathrm{~h}$.

\section{Characterization}

The GG, GG-g-AMPS, GG-g-poly(AMPS-co-DMAPMA)8, and GG-g-poly(AMPS-co-DMAPMA)/MMT-3 samples 
were characterized using FTIR, TGA, SEM, and XRD techniques. The FTIR were recorded using FTIR-Prestige21, Shimadzu Japan, in the range of $4000-400 \mathrm{~cm}^{-1}$ wavenumber during 40 scans, with a resolution of $2 \mathrm{~cm}^{-1}$. Thermograms were recorded using standard DSC-TGA (Q600 V20.9 model) Japan, by heating the samples in the ranges of $30-700{ }^{\circ} \mathrm{C}$, under a nitrogen atmosphere at $10^{\circ}$ $\mathrm{C} / \mathrm{min}$. Surface morphology of the samples was obtained on gold coating JOEL JSM-6380LA analytical Scanning electron microscope (SEM) under magnification of 2000 at $20 \mathrm{kV}$. XRD pattern was recorded on X-ray diffractometer (Rigatu Miniflex 600-XRD instrument, USA) using Cu Kó radiation generated at $35 \mathrm{kV}$ and $35 \mathrm{~mA}$ in the differential angle $2 \theta$ at a range of $0^{\circ}-80^{\circ}$ in steps of $0.020 / \mathrm{s}$.

\section{Swelling studies}

Swelling experiments of the GG-g-poly(AMPS-coDMAPMA)-8 and GG-g-poly(AMPS-co-DMAPMA)/MMT3 samples were carried out in different media $(\mathrm{pH}$ and salts solution). A known amount of the samples were weighed and immersed into swelling media at room temperature. After specified interval of time, the samples were removed and the excess surface water was wiped away gently using blotting (tissue) paper and re-weighed. This procedure was repeated until equilibrium is reached. The data were reported as the mean of three different measurements. The effects of nature of different salts solution $(0.1 \mathrm{M})$ on the swelling ratio were also studied in the same manner.

The swelling ratio (SR) and swelling equilibrium $\left(S_{\mathrm{eq}}\right)$ were calculated by the following equations:

$\operatorname{SR}(g / g)=\frac{\left(W_{\mathrm{t}}-W_{\mathrm{o}}\right)}{W_{\mathrm{o}}}$,

$S_{\text {eq }}(g / g)=\frac{\left(W_{\mathrm{e}}-W_{0}\right)}{W_{\mathrm{o}}}$,

where $W_{0}, W_{\mathrm{t}}$, and $W_{\mathrm{e}}$ are the weight of the gel at time $t=0, t=t$, and at equilibrium, respectively [28].

\section{Dyes adsorption studies}

A known amount of GG-g-poly(AMPS-co-DMAPMAm)-8 and GG-g-poly(AMPS-co-DMAPMAm)/MMT-3 samples were left immersed in $100 \mathrm{mg} / \mathrm{L}$ solutions of $\mathrm{RhB}$ and $\mathrm{C} 2 \mathrm{R}$ dyes. At different time intervals, $2.5 \mathrm{~mL}$ of the supernatant solution were withdrawn and the absorbance values were measured using UV-visible spectrophotometer (UV-1800 Shimadzu, Japan) $\lambda_{\max }$ of 554 and $510 \mathrm{~nm}$ for RhB and $\mathrm{C} 2 \mathrm{R}$, respectively. Calibration curves were used to convert the absorbance measured into concentration using standard solutions of $2,4,6,8$, and $10 \mathrm{mg} / \mathrm{L}$ of the dyes. Different initial concentrations $(10,30,50,70$, and $100 \mathrm{mg} / \mathrm{L})$ were used for equilibrium adsorption studies by immersing varied amount of the adsorbent and allowed to stand for $14 \mathrm{~h}$ and the resultant solutions were decanted and the absorbance were recorded. The amount of dyes adsorbed at time $t\left(q_{\mathrm{t}}\right)$ and at equilibrium $\left(q_{\mathrm{e}}\right)$ in $\mathrm{mg} / \mathrm{g}$ was calculated using the following equations $[29,30]$ :

$q_{\mathrm{t}}=\frac{\left(C_{0}-C_{\mathrm{t}}\right)}{M} \times V$,

$q_{\mathrm{e}}=\frac{\left(C_{0}-C_{\mathrm{e}}\right)}{M} \times V$,

where $q_{\mathrm{t}}$ and $q_{\mathrm{e}}$ are the amount of dyes adsorbed $(\mathrm{mg} / \mathrm{g})$ at time $t=t$ and at equilibrium, respectively. $C_{0}, C_{\mathrm{t}}$, and $C_{\mathrm{e}}$ are dyes concentration $(\mathrm{mg} / \mathrm{L})$ at time $t=0, t=t$, and at equilibrium, respectively, $M$ is the weight of the gel $(\mathrm{g})$ and $V$ is the volume (L) of the dye solution.

\section{Results and discussion}

The composite hydrogels were prepared by crosslink copolymerization of AMPS, DMAPMAm, and MBA in water in the presence of GG. MMT was incorporated in situ in the copolymer network. During the polymerization reaction, the bi-functional MBA copolymerizes with AMPS and DMAPMAm to form a network, while GG takes part in the free-radical polymerization reaction by forming macroradicals [31]. Thus, a composite gel is formed by entrapment of MMT clay in the copolymer network. The free-radical reaction mechanism along with the formation of the gel network is shown in Scheme 1.

The composition of the gels/composites and the percentage yield is presented in Table 1. The optimized product [GG-g-poly(AMPS-co-DMAPMAm)-8] was used for composite formation and used as representative sample for swelling and dye adsorption studies. The grafting conditions were optimized by varying monomer (DMAPMAm and AMPS) contents and keeping all other parameters constant.

The GP increases as the AMPS content increases from 0.1 to $0.25 \mathrm{~g}$, and decreases as AMPS content increases to $0.30 \mathrm{~g}$ (Table 1). For DMAPMAm, the GP follows a similar pattern as in AMPS. The decreases in GP as the content of monomers increases could be attributed to the less reactive side on the GG as its content remains constant, and hence, there are more molecules of DMAPMAm and AMPS than GG and this could lead to the formation of homopolymer and hence low yield.

\section{FTIR}

FTIR Spectra of GG, GG-g-AMPS, GG-g-poly(AMPS-coDMAPMAm)-8, and GG-g-poly(AMPS-co-DMAPMAm)/ MMT-3 composite gels are shown in Fig. 1. The spectrum 

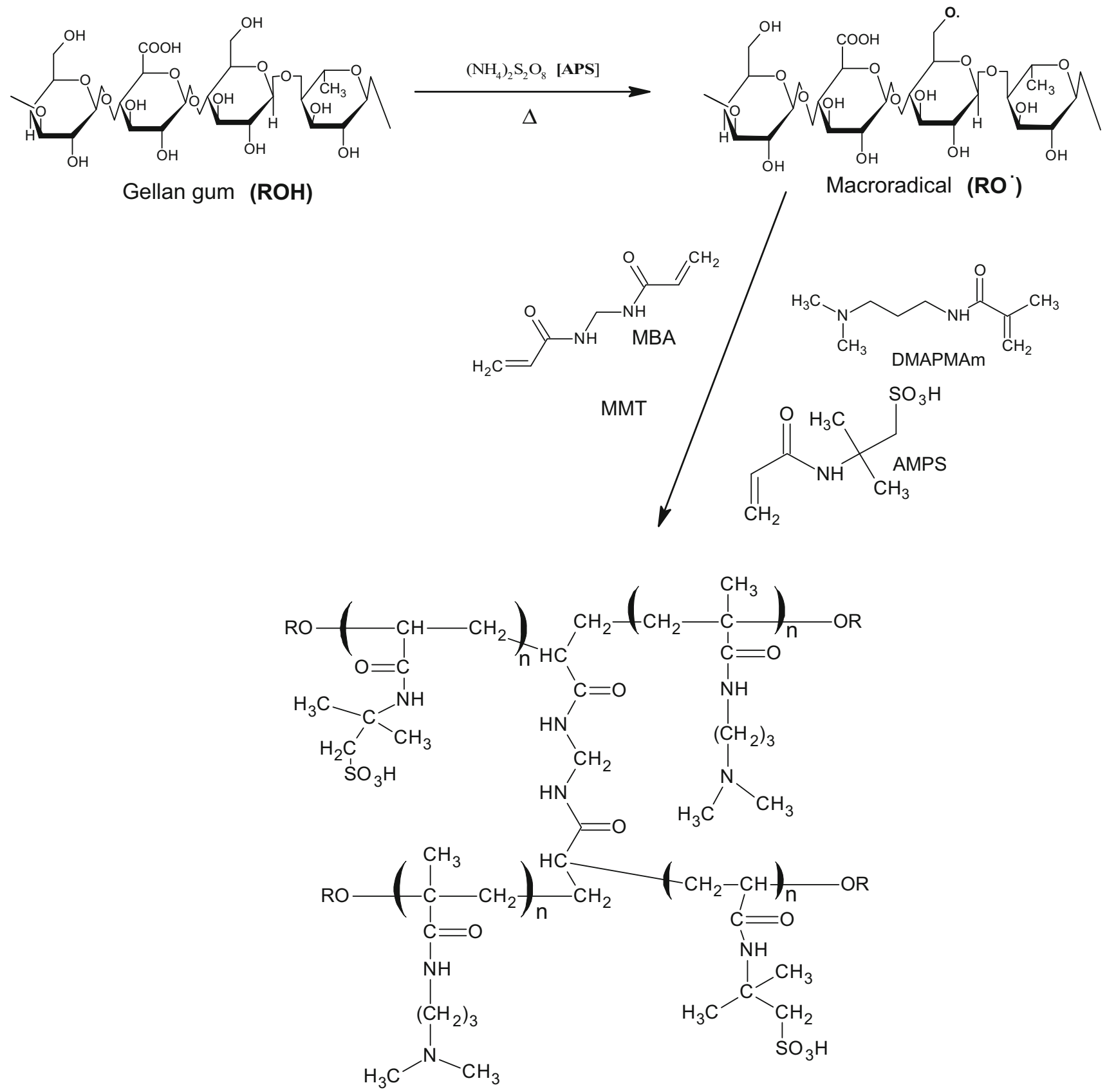

Scheme 1 Proposed scheme for the formation of GG-g-poly(AMPS-co-DMAPMAm) gel

(Fig. 1a) showed a broad absorption band at $3290 \mathrm{~cm}^{-1}$ which is due to stretching of $\mathrm{O}-\mathrm{H}$ and a medium absorption peak at $2926 \mathrm{~cm}^{-1}$ corresponding to the $\mathrm{C}-\mathrm{H}$ stretching of $\mathrm{CH}_{2}$ groups. The absorption at $1605 \mathrm{~cm}^{-1}$ is related to the $\mathrm{C}=\mathrm{O}$ stretching of $\mathrm{COO}^{-}$of the GG. The peak at $1016 \mathrm{~cm}^{-1}$ is assigned to $\mathrm{C}-\mathrm{O}$ bond stretching frequencies [32]. Comparing the GG and GG-g-AMPS (Fig. 1b) spectra, new characteristic peaks were observed at 1643, 1438, and $923 \mathrm{~cm}^{-1}$ which are attributed to asymmetric stretching vibration of $\mathrm{C}=\mathrm{O}, \mathrm{C}-\mathrm{N}$ stretching, and $\mathrm{S}-\mathrm{O}$ stretching of the $\mathrm{SO}_{3} \mathrm{H}$, respectively [33]. The additional characteristic absorption bands of 1537 and $2771 \mathrm{~cm}^{-1}$ for $\mathrm{N}-\mathrm{H}$ stretching and $\mathrm{C}-\mathrm{H}$ stretching of $-\mathrm{N}\left(\mathrm{CH}_{3}\right)_{2}$ of DMAPMAm [25] were observed in the spectra of GG-g-poly(AMPS-coDMAPMAm)-8 (Fig. 1c). Similarly, in addition to the peaks on the spectra (Fig. 1a-c), peaks at 1040, 814, and $621 \mathrm{~cm}^{-1}$ for $\mathrm{Si}-\mathrm{O}-\mathrm{Si}, \mathrm{Al}-\mathrm{Al}-\mathrm{OH}$, and $\mathrm{Si}-\mathrm{Al}-\mathrm{OH}$ [34], respectively, were observed on the spectrum of GG-g-poly (AMPS-co-DMAPMAm)/MMT-3 (Fig. 1d) indicating the entrapment of MMT on the gel matrices. 
Table 1 Composition of hydrogels/composite and percentage yield

\begin{tabular}{|c|c|c|c|c|c|c|c|c|c|}
\hline Gel & Code & GG $(g)$ & $\begin{array}{l}\text { AMPS } \\
(\mathrm{g})\end{array}$ & $\begin{array}{l}\text { DMAPMAm } \\
(\mathrm{g})\end{array}$ & $\begin{array}{l}\text { APS } \\
(\mathrm{g})\end{array}$ & $\begin{array}{l}\text { MBA } \\
(\mathrm{g})\end{array}$ & MMT & $\mathrm{GP}(\%)$ & $\begin{array}{l}\text { Yield } \\
(\%)\end{array}$ \\
\hline \multirow[t]{10}{*}{ GG-g-poly(AMPS-co-DMAPMAm) } & 1 & 0.1 & 0.1 & 0.15 & 0.05 & 0.05 & & 63.18 & 57.87 \\
\hline & 2 & 0.1 & 0.1 & 0.20 & 0.05 & 0.05 & & 64.08 & 60.32 \\
\hline & 3 & 0.1 & 0.15 & 0.20 & 0.05 & 0.05 & & 72.91 & 58.73 \\
\hline & 4 & 0.1 & 0.15 & 0.25 & 0.05 & 0.05 & & 73.81 & 69.80 \\
\hline & 5 & 0.1 & 0.20 & 0.25 & 0.05 & 0.05 & & 79.13 & 50.91 \\
\hline & 6 & 0.1 & 0.20 & 0.30 & 0.05 & 0.05 & & 79.72 & 62.32 \\
\hline & 7 & 0.1 & 0.25 & 0.30 & 0.05 & 0.05 & & 89.12 & 68.92 \\
\hline & 8 & 0.1 & 0.25 & 0.40 & 0.05 & 0.05 & & 89.82 & 79.56 \\
\hline & 9 & 0.1 & 0.30 & 0.40 & 0.05 & 0.05 & & 88.12 & 64.39 \\
\hline & 10 & 0.1 & 0.30 & 0.50 & 0.05 & 0.05 & & 87.65 & 63.87 \\
\hline \multicolumn{10}{|l|}{ Composite } \\
\hline \multirow[t]{3}{*}{ GG-g-poly(AMPS-co-DMAPMAm)/MMT } & 1 & 0.1 & 0.25 & 0.40 & 0.05 & 0.05 & 0.01 & 59.23 & 69.21 \\
\hline & 2 & 0.1 & 0.25 & 0.40 & 0.05 & 0.05 & 0.02 & 59.87 & 67.12 \\
\hline & 3 & 0.1 & 0.25 & 0.40 & 0.05 & 0.05 & 0.03 & 58.94 & 74.18 \\
\hline
\end{tabular}

Fig. 1 FTIR spectra of a GG, b GG-g-APMS, c GG-g-poly (AMPS-co-DMAPMAm)-8, and d GG-g-poly(AMPS-coDMAPMAm)/MMT-3

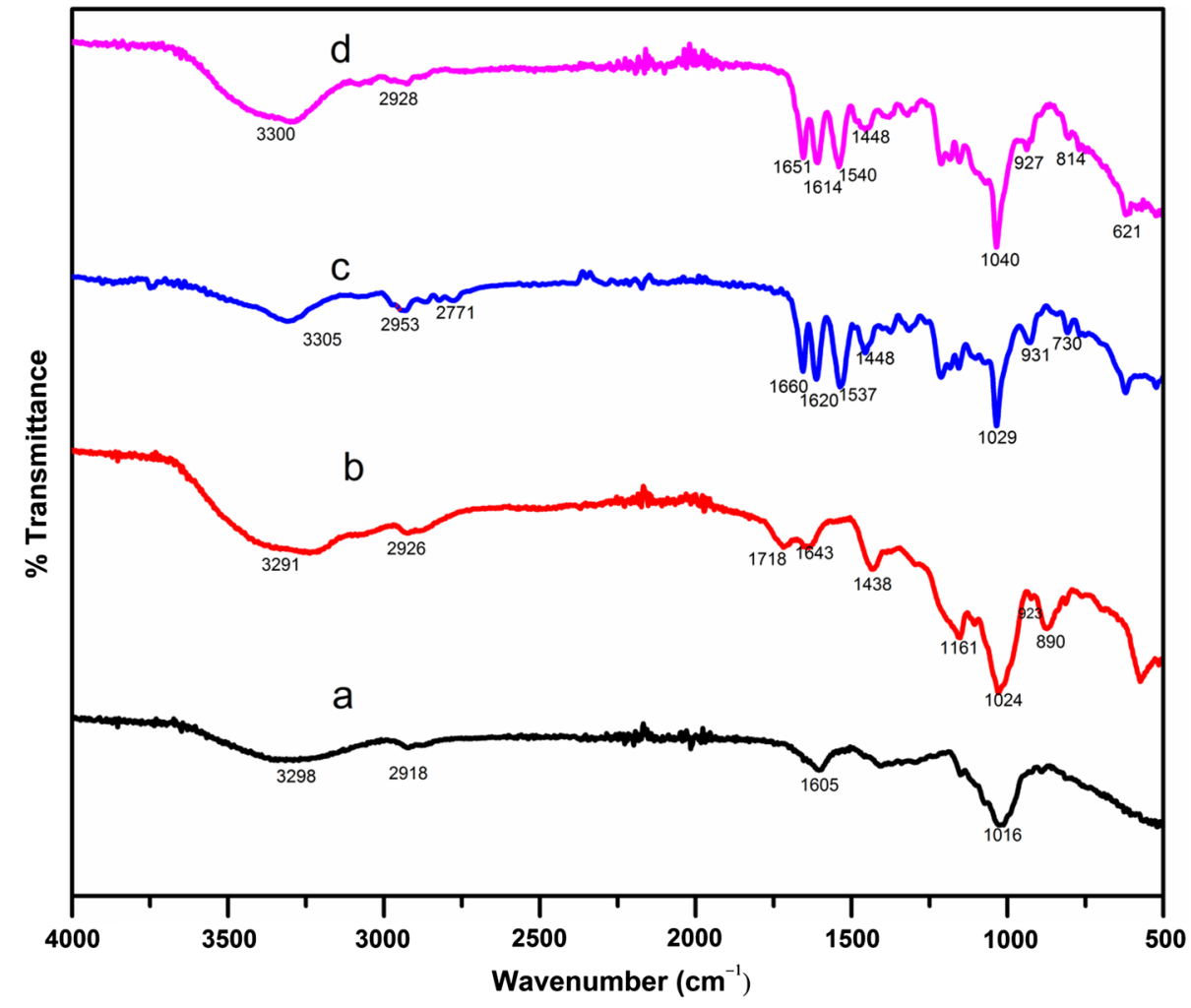

\section{TGA}

The thermograms of GG, GG-g-AMPS, GG-g-poly (AMPS-co-DMAPMAm)-8, and GG-g-poly(AMPS-coDMAPMAm)/MMT-3 are presented in Fig. 2. GG (Fig. 2a) shows three degradation steps. The first step of degradation occurs between temperatures of $35-100{ }^{\circ} \mathrm{C}$ with the weight loss of $14 \%$, and is attributed to the loss of moisture content in the polysaccharide. The second step of the decomposition occurs in the range of $210-260{ }^{\circ} \mathrm{C}$ with a major weight loss of $36 \%$ due to the breaking of the glycosidic linkage of the GG. The final decomposition of GG occurs around $270-540{ }^{\circ} \mathrm{C}$ with the weight loss of $32 \%$. About $14 \%$ of the GG sample remains as residual matter at 


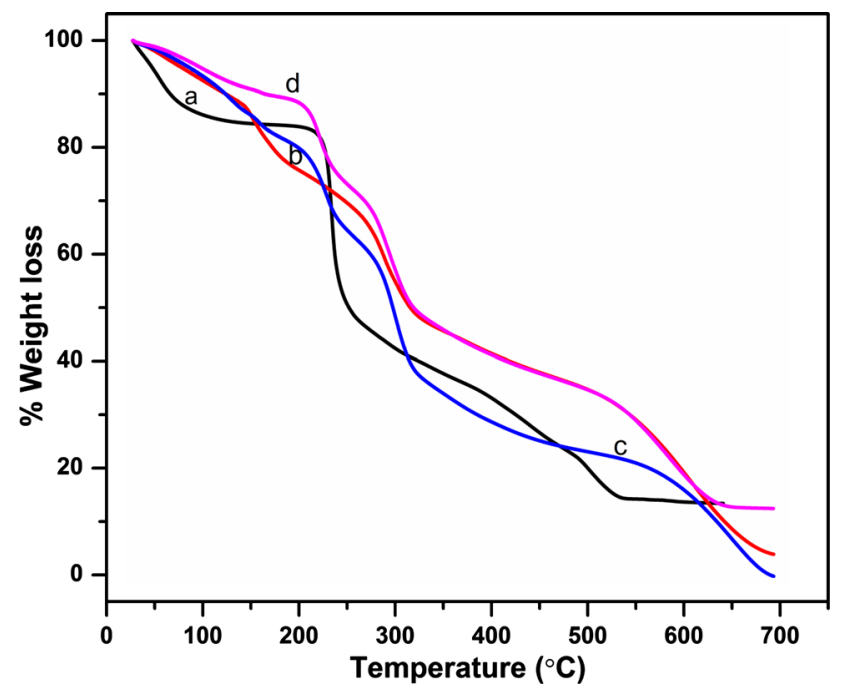

Fig. 2 Thermograms of a GG, b GG-g-APMS, c GG-g-poly(AMPSco-DMAPMAm)-8, and d GG-g-poly(AMPS-co-DMAPMAm)/ MMT-3

$550{ }^{\circ} \mathrm{C}$. For GG-g-AMPS (Fig. 2b), four decomposition steps occur. With the first step in the range of $30-140{ }^{\circ} \mathrm{C}$ with a weight loss of $13 \%$ due to loss of moisture in the sample and $10 \%$ weight loss between 182 and $265^{\circ} \mathrm{C}$, this might be due to the dissociation of GG from AMPS. Between 320 and $520{ }^{\circ} \mathrm{C}$, a major weight loss (17\%) occurred and is linked to the degradation of the polysaccharide and final step decomposition at $555{ }^{\circ} \mathrm{C}$ with $25 \%$ weight loss leaving $4 \%$ as the residue. The thermogram of GG-g-poly(AMPS-co-DMAPMAm)-8 (Fig. 2c) shows four degradation steps with the first step losing $16 \%$ of the weight between 35 and $160{ }^{\circ} \mathrm{C}$ due to the elimination of moisture from the system. The second steps occurred in the range of $324-510{ }^{\circ} \mathrm{C}$ with the loss of $18 \%$ which could be due to the breaking of the grafting between GG and the copolymers. The third degradation step results in weight loss of $28 \%$ between the temperature range of $324-510{ }^{\circ} \mathrm{C}$. The complete degradation of the grafted gel occurred around $580{ }^{\circ} \mathrm{C}$. For the GG -g-poly(AMPS-co-DMAPMAm)/MMT-3 (Fig. 2d), the degradation steps are similar to that of GG-g-AMPS and are in four stages. The first was the elimination of water molecule from the composite gel in the range of $33-180{ }^{\circ} \mathrm{C}$. The second steps of the degradation occurred in the temperature range of 205$256{ }^{\circ} \mathrm{C}$ with a weight loss of $16 \%$ and could be due to the degradation of GG. The third step occurred between 317 and $535{ }^{\circ} \mathrm{C}$ with major weight loss of $20 \%$ and the final step of degradation occurred at $633{ }^{\circ} \mathrm{C}$ leaving around $13 \%$ as residual matter. The GG-g-AMPS, and GG-g-poly (AMPS-co-DMAPMAm)-8 showed low thermal stability compared GG and GG-g-poly(AMPS-co-DMAPMAm)/ MMT-3. The high stability of GG-g-poly(AMPS-co-
DMAPMAm)/MMT-3 toward heat is attributed to the incorporation of MMT in the system [35].

\section{SEM}

The surface morphology of GG, GG-g-AMPS, GG-g-poly (AMPS-co-DMAPMAm)-3, and GG-g-poly(AMPS-coDMAPMAm)/MMT-8 is presented in Fig. 3. It could be deduced from Fig. 3b that grafting of AMPS on the GG changes the fibrous homogeneous surface of GG (Fig. 3a) into heterogeneous. Likewise, Fig. 3c shows a very distinct crystalline-like morphology suggesting the grafting of GG on poly(AMPS-co-DMAPMAm)-8. On the other hand, exfoliating MMT in the system also shows a considerable change in the surface morphology producing cotton like accumulation with an irregular shape that appears fibrous (Fig. 3d).

\section{XRD}

The XRD patterns of MMT, GG, GG-g-AMPS, GG-g-poly (AMPS-co-DMAPMAm)-8, and GG-g-poly(AMPS-coDMAPMAm)/MMT-3 samples are shown in Fig. 4. MMT diffractogram (Fig. 4a) shows a complete amorphous nature of the clay MMT. GG diffractogram (Fig. 4b) showed two major peaks at $2 \theta$ values of $21.31^{\circ}$ (medium) and $30.47^{\circ}$ (sharp). The exhibition of this sharp peak at lower $2 \theta$ value indicated the crystalline nature of the GG. In GGg-AMPS sample (Fig. 4c); the disappearance of some peaks and appearing of new one at a $2 \theta$ value of $5.82^{\circ}$ indicated the grafting of AMPS on GG. The appearance of many sharp peaks at low $2 \theta\left(9.92^{\circ}, 14.12^{\circ}\right.$ and $\left.16.32^{\circ}\right)$ values (Fig. 4d) indicated the incorporation of DMAPMAm on GG-g-AMPS and it further indicates the semicrystalline nature of the gel network [36]. The intercalation of MMT within the polymer gel network is evidence of the major shift of the peak from the $2 \theta$ value of $18.79^{\circ}$ (Fig. 4d) to $22.18^{\circ}$. Similarly, the increases of d-spacing for MMT to $11.4527 \AA$ from the normal $9.8 \AA$ [34] are another evidence to show the intercalation of MMT into the gel network. The decrease in the intensity of the peak around $2 \theta$ value of 9.1 and the disappearance of the peak at $2 \theta$ of $7.2^{\circ}$ from Fig. $4 \mathrm{~d}$ are further evidences to prove the intercalation of MMT into the gel matrix. The disappearance of a small broad peak at a $2 \theta$ value of $31.69^{\circ}$ in Fig. 4e also showed the intercalation of MMT into the gel network which resulted in decreases in the degree of crystallinity [37].

\section{Swelling responsive in different salt solution}

The effect of different salt solution (Fig. 5) on the swelling ratio of GG-g-poly(AMPA-co-DMAPMAm)-8 and GG-gpoly(AMPA-co-DMAPMAm)/MMT-3 samples shows 

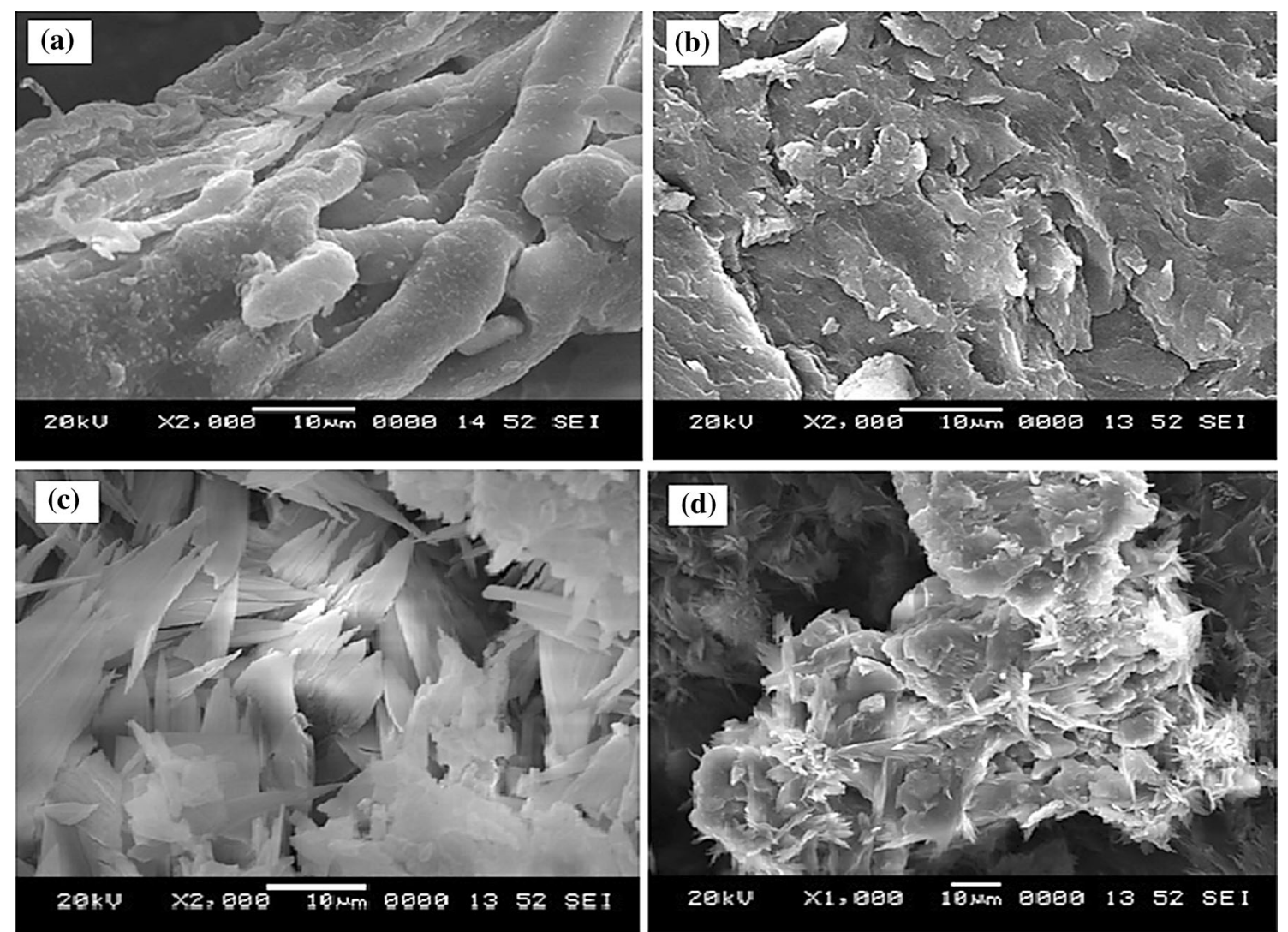

Fig. 3 SEM images of a GG, b GG-g-AMPS, c GG-g-poly(AMPS-co-DMAPMAm)-8, and d GG-g-poly(AMPS-co-DMAPMAm)/MMT-3

Fig. 4 XRD diffractograms of a MMT, b GG, c GG-g-AMPS, d GG-g-poly(AMPA-coDMAPMAm)-8, and e GG-gpoly(AMPA-co-DMAPMAm)/ MMT-3

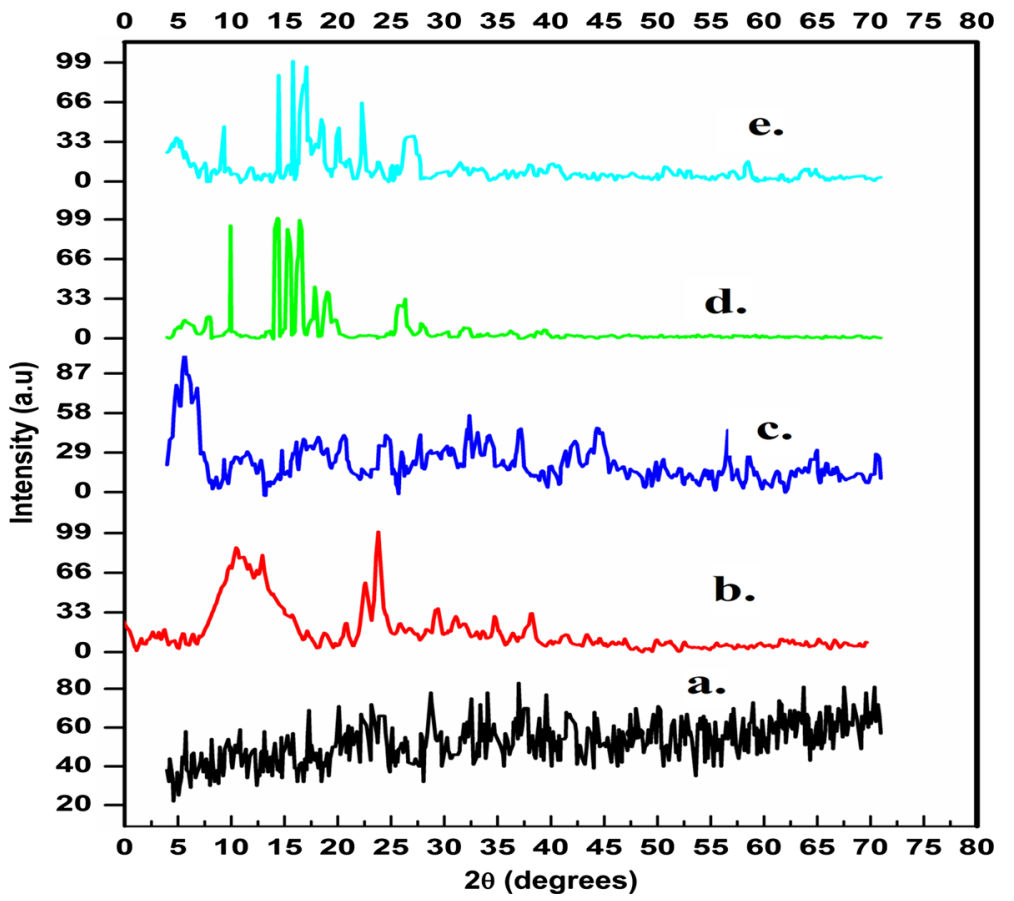

higher swelling capacity in $\mathrm{NaCl}$ solution compared to other salt solution with the least swelling response in $\mathrm{FeCl}_{3}$. The swelling behavior is affected by many factors such as nature of cations (charge and radius of cations). The greater the charge of cations, the greater the cross linking degree which results in decrease in swelling [28]. 


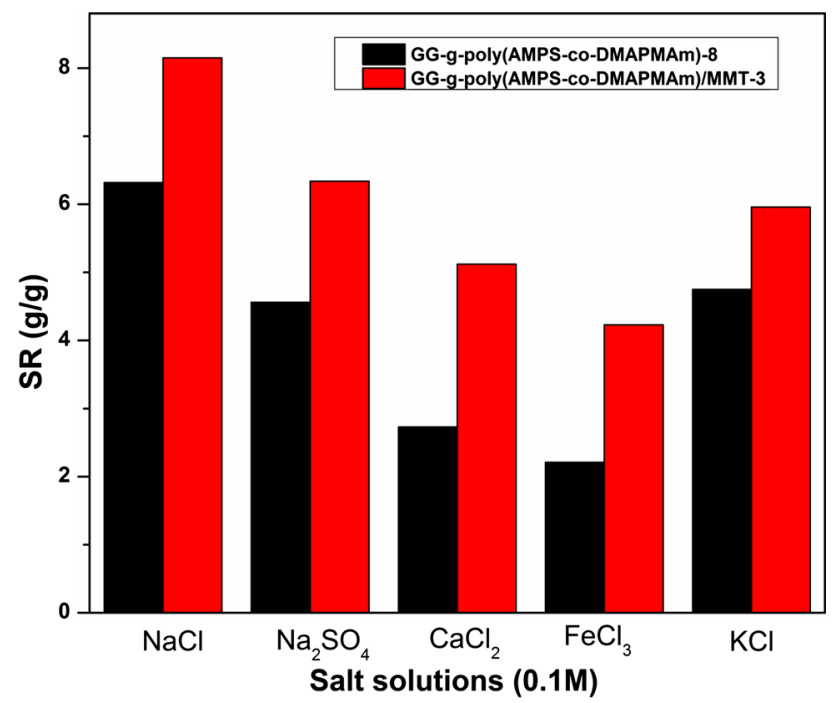

Fig. 5 Effects of different salt solution $(0.1 \mathrm{M})$ on swelling ratio of GG-g-poly(AMPS-co-DMAPMAm)-8 and GG-g-poly(AMPS-coDMAPMAm)/MMT-3

The swelling of the gel is due to osmotic pressure difference developed between the gel and the external salt solution due to the charge screening effect of the salt solution. The composite hydrogels exhibited salt sensitivity as reported in the literature $[38,39]$.

\section{Effect of pH on the swelling ratio}

The swelling ratios of the gel in different $\mathrm{pH}$ media were studied and the results reported in Fig. 6a. Figure 6 showed higher swelling ratio (SR) in basic medium ( $\mathrm{pH} 9.0)$ with lower SR in acidic medium (pH 1.2) by GG-g-poly(AMPSco-DMAPMAm)-8. The presence of free amino group on DMAPMAm leads to the formation of many hydrogen bonds in an alkaline medium which will restrict the relaxation of network chain. While in acidic medium, the free amino group is expected to ionize which may result in the breakage of hydrogen bond and generate electrostatic repulsion on the polymer chain [40]. In acidic medium, the attraction between $\mathrm{SO}_{3}{ }^{2-}$ and quaternary ammonium group restricts the swelling [41]. Furthermore, the carbonyl group of the AMPS and DMAPMAm forms hydrogen bonding with the GG which also aids in reducing the swelling $[42,43]$.

\section{Swelling kinetics}

The mechanisms of swelling studies for the gel/composite were carried out based on the standard methods reported in the literature [44, 45]. The swelling parameters of the gel/composite were determined from the various plots (Figs. 6,7). The parameters such as swelling equilibrium ratio $\left(S_{\mathrm{eq}}\right)$ in gram of water per gram of gel/composite, initial swelling rate $\left(R_{\mathrm{j}}\right)$ in $\mathrm{g}$ of water/g gel/composite $\mathrm{min}^{-1}$, swelling rate constant $\left(K_{\mathrm{s}}\right)$, in $\mathrm{g}$ gel/composite/g water $\min ^{-1}$ ), swelling exponent $(n)$, and maximum equilibrium swelling $\left(S_{\max }\right)$ in $\mathrm{g}$ of water $\mathrm{g}^{-1}$ of sample were calculated using the dynamic swelling data obtained from various plots shown in Figs. 6 and 7. The swelling mechanism of the gel/composite was experimentally determined by employing a second-order kinetic equation as follows:

$\frac{\mathrm{d} s}{\mathrm{~d} t}=k_{\mathrm{s}}\left(s_{\mathrm{eq}}-s\right)^{2}$,

where $k_{\mathrm{s}}$ and $s_{\mathrm{eq}}$ are the swelling rate constant and degree of swelling at equilibrium, respectively. The above equation on integration over the limit $S=S_{0}$ at $t=t_{\mathrm{o}}$ and $S=S$ at $t=t$ gives

$\frac{t}{\mathrm{SR}}=\frac{1}{k_{\mathrm{S}} s_{\mathrm{eq}}^{2}}+\frac{1}{s_{\mathrm{eq}}} t$

where $k_{\mathrm{s}} s_{\mathrm{eq}}^{2}$ is equal to $R_{\mathrm{i}}$ which is the initial swelling rate, $s_{\text {eq }}$ is the equilibrium swelling, and $k_{\mathrm{s}}$ is the swelling rate constant. The plot of $t / \mathrm{SR}$ vs $t$ (Figs. 6b, 7b) produced a linear straight line with a slope of $1 / s_{\text {eq }}$ and intercept of $\frac{1}{k_{s} s_{e q}^{2}}$. This indicates that the second-order kinetics is followed by the swelling process. Furthermore, the calculated $s_{\mathrm{eq}}$ from the slope are in good agreement with the experimental value as shown in Table 2. The initial swelling rate $\left(R_{\mathrm{i}}\right)$ of the GG-g-poly(AMPS-coDMAPMAm)/MMT-3 decreases drastically from acidic to basic medium. A similar finding was reported [45]. However, the swelling rate constant $\left(k_{\mathrm{s}}\right)$ increases as the $\mathrm{pH}$ values increase.

The mechanism of diffusion is one of the factors that govern the applicability of materials [42]. The absorption process involves the diffusion of water molecules into the free spaces of the materials which increase the segmental mobility and consequently result in an expansion of chain segment between crosslink and later result in swelling. The dynamics of water sorption process was studied using the simple empirical equation called power law equation which is used mostly in determining the mechanism of diffusion in the polymeric network [46]:

$F=\mathrm{Kt}^{\mathrm{n}}$.

The above equation can be rewritten in form of $\ln$ as follows:

$\ln F=\ln K+n \ln t$.

The values of $K$ and $n$ were calculated from the intercept and slope of $\operatorname{lnF}$ vs $t$ plots (Figs. 6c, 7c) and tabulated in Table 2, where $F, n$, and $K$ are swelling power, swelling exponent, and swelling rate constant, respectively. 

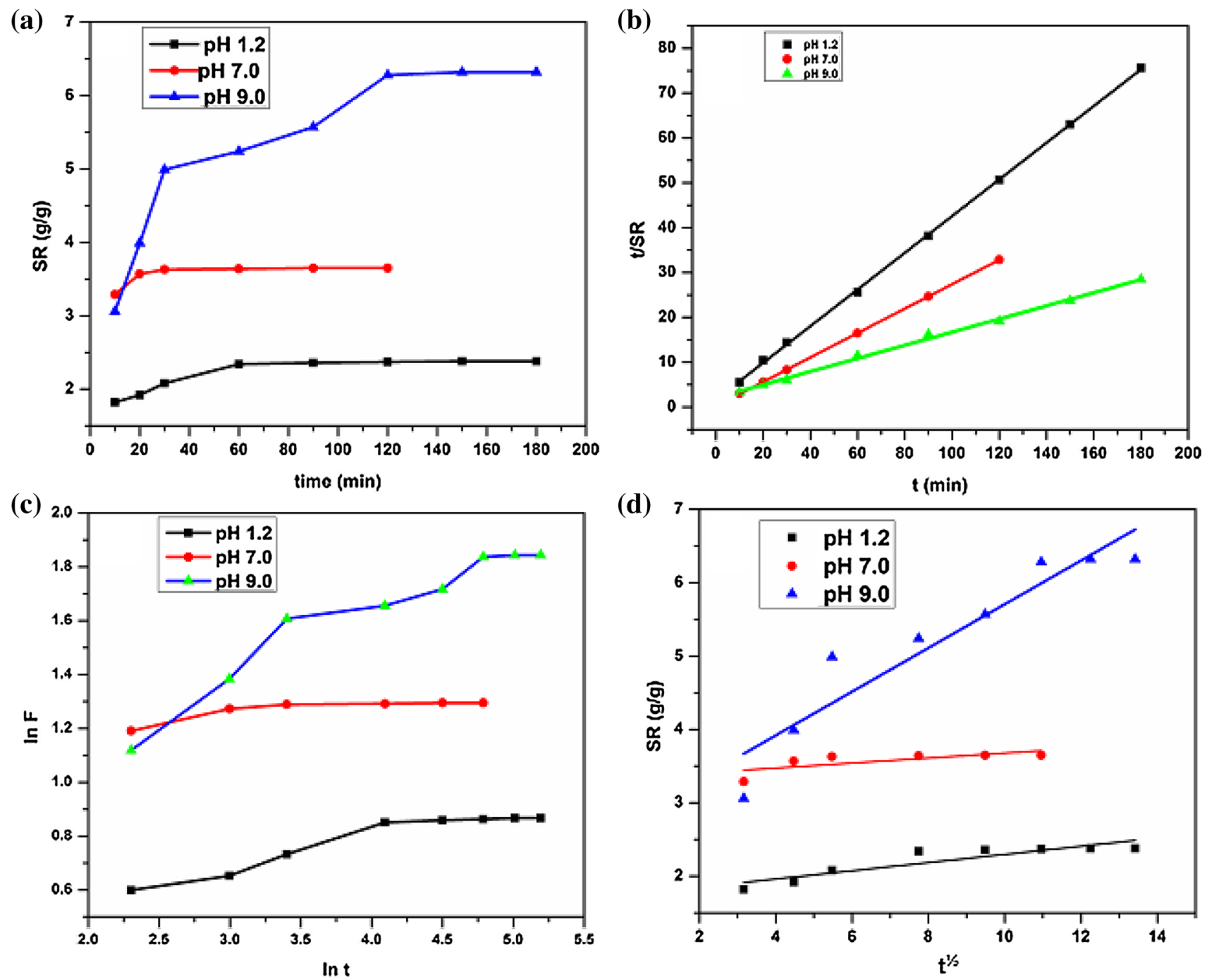

Fig. 6 Swelling curves for GG-g-poly(AMPS-co-DMAPMAm)-8 gel

Depending on the diffusion rate of the material relaxation, three different diffusion mechanisms are proposed [42-45, 47]:

1. Fickian diffusion in which the diffusion rate is less than the relaxation rate $(n=0.50)$;

2. Diffusion which is rapid compared the relaxation processes $(n=1)$; and

3. Non-Fickian or anomalous diffusion which occurs when the rate of diffusion and that of relaxation are comparable $(0.50<n<1)$.

The Fickian diffusion, actually, refers to a situation where water penetration rate in the gels is less than the polymer chain relaxation rate. Therefore, $n=0.5$ indicates a perfect Fickian process. Nevertheless, when the water penetration rate is much below the polymer chain relaxation rate, it is possible to record the $n$ values below 0.5 . This situation is still regarded as Fickian diffusion or "Less

Fickian diffusion" behavior [46]. In this study, the values of $n$ (Table 2) are all below 0.5. Hence, it is said to follow a less Fickian diffusion mechanism.

\section{Dye adsorption studies}

The dye adsorption studies were carried out using rhodamine $\mathrm{B}$ and chromotrope $2 \mathrm{R}$ as model dyes and their structures are given in Fig. 8.

\section{Effects of contact time on the adsorption capacity}

The effect of contact time on the adsorption of dyes $\mathrm{RhB}$ and $\mathrm{C} 2 \mathrm{R}$ on both GG-g-poly(AMPS-co-DMAPMAm)-8 and GG-g-poly(AMPS-co-Dmapmam)/MMT-3 (Fig. 9) showed an increase in the adsorption capacity slowly with increase in time. RhB showed higher adsorption compared to $\mathrm{C} 2 \mathrm{R}$; this could be attributed to the presence of many 

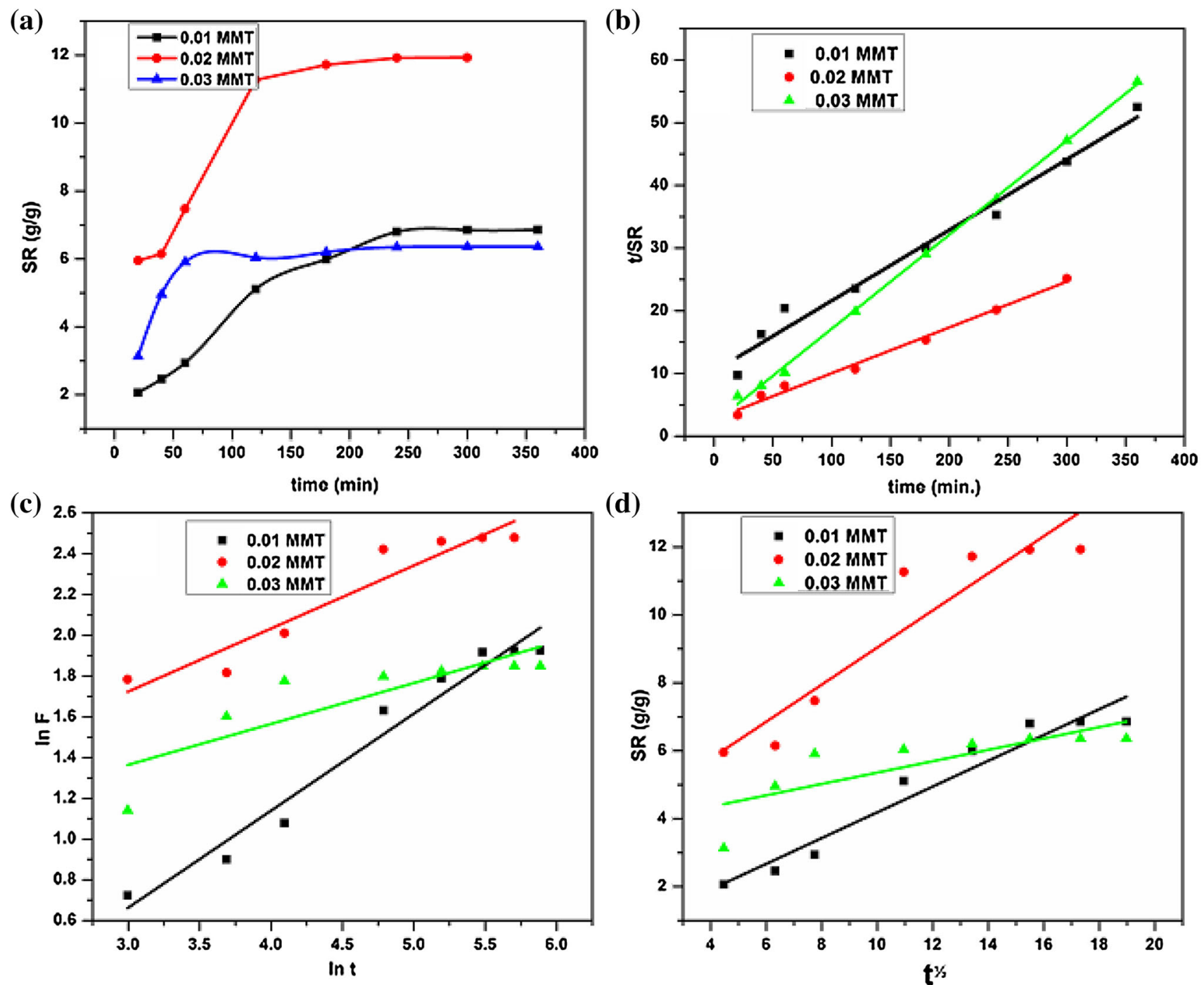

Fig. 7 Swelling curves for GG-g-poly(AMPS-co-DMAPMAm)/MMT-3

Table 2 Kinetics swelling and diffusion parameters of GG-gpoly(AMPS-co-DMAPMAm)-8 and GG-g-poly(AMPS-coDMAPMAm/MMT-3

\begin{tabular}{|c|c|c|c|c|c|c|}
\hline $\mathrm{PH}$ & $S_{\text {eq }}(\mathrm{g} / \mathrm{g})$ & $R_{\mathrm{i}}(\mathrm{g}$ of water/g of sample) & $K_{\mathrm{s}}(\mathrm{g} / \mathrm{g})$ & $N$ & $K$ & $S_{\max }$ \\
\hline \multicolumn{7}{|c|}{ GG-g-poly(AMPS-co-DMAPMAm)-8 } \\
\hline 1.2 & 2.45 & 1.69 & 0.099 & 0.10 & 1.03 & 2.38 \\
\hline 7.0 & 3.68 & 0.20 & 0.379 & 0.04 & 7.48 & 3.65 \\
\hline 9.0 & 6.85 & 2.07 & 0.010 & 0.24 & 2.40 & 6.32 \\
\hline \multicolumn{7}{|c|}{ GG-g-poly(AMPS-co-DMAPMAm/MMT-3 } \\
\hline 1.2 & 8.93 & 10.33 & 0.0012 & 0.48 & 3.733 & 6.86 \\
\hline 7.0 & 13.70 & 2.71 & 0.0020 & 0.31 & 4.383 & 11.93 \\
\hline 9.0 & 6.67 & 2.12 & 0.0106 & 0.2 & 3.679 & 6.36 \\
\hline
\end{tabular}

negative (acidic groups) site on the adsorbent which could result in the formation of an electrostatic attraction with the positive (basic groups) part of the adsorbate. The adsorption of $\mathrm{C} 2 \mathrm{R}$ on both the adsorbents is proceeded at slower rate especially on the GG-g-poly(AMPS-co-DMAPMAm)/ MMT-3. This could be due to the repulsion between the anionic (basic site) groups on both $\mathrm{C} 2 \mathrm{R}$ and the composites [48]. 
Fig. 8 Structures of the dyes used: a rhodamine B and b chromotrope $2 \mathrm{R}$

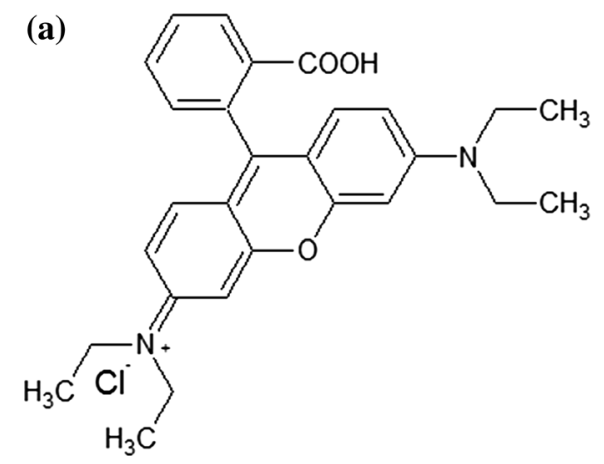

(b)<smiles>O=S(=O)(O)c1cc2ccc(S(=O)(=O)O[Na])c(O)c2c(O)c1/N=N/c1ccccc1</smiles>

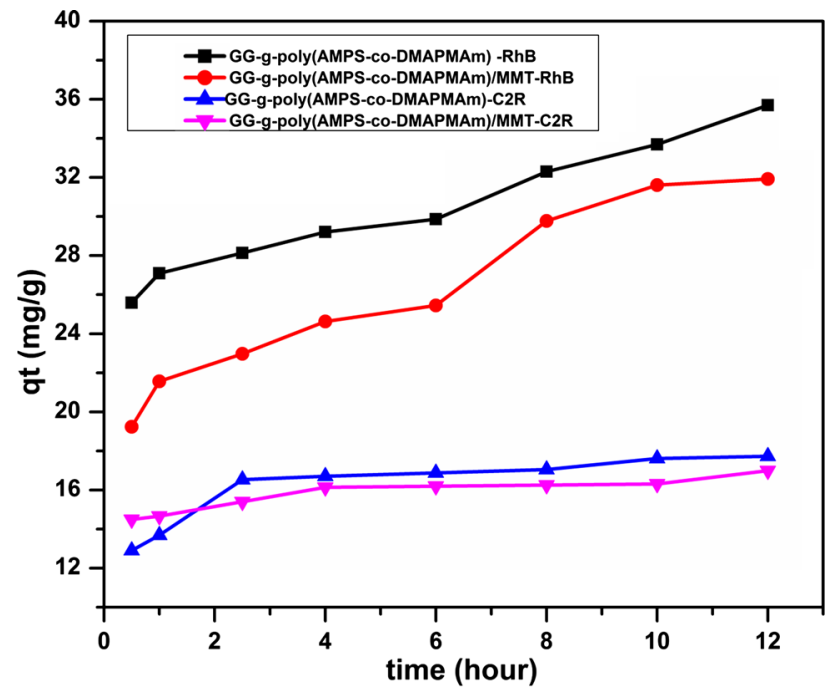

Fig. 9 Amount of dyes (rhodamine B and chromotrope 2R) adsorbed (mg/g) on GG-g-poly(AMPS-co-DMAPMAm)-8 gel and GG-g-poly (AMPS-co-DMAPMAm)/MMT-3 composite over time

\section{Adsorption isotherm}

Adsorption isotherms usually describe the performance of adsorbents in adsorption processes by describing the surface interaction between the adsorbent and adsorbate [49]. There are various isotherm models used to describe the adsorption processes. In this study, the two most common used adsorption isotherms, namely, Langmuir isotherm [50, 51] and Freundlich isotherm [52], are employed.

The Langmuir isotherm is a model which quantitatively describes equilibrium monolayer adsorbate formation on the surface of the adsorbent, and is expressed as follows:

$\frac{C_{\mathrm{e}}}{q_{\mathrm{e}}}=\frac{1}{q_{\mathrm{m}}} \times C_{\mathrm{e}}+\frac{1}{K_{\mathrm{L}} q_{\mathrm{m}}}$,

where $C_{\mathrm{e}}$ and $q_{\mathrm{e}}$ are the equilibrium concentration of dye $(\mathrm{mg} / \mathrm{L})$ and the amount of dye adsorbed $(\mathrm{mg} / \mathrm{g})$, respectively, $q_{\mathrm{m}}$, is the maximum adsorption corresponding to complete monolayer coverage on the surface $(\mathrm{mg} / \mathrm{g}), K_{\mathrm{L}}$ is the Langmuir constant which is related to the energy of adsorption $(\mathrm{L} / \mathrm{mg}) . K_{\mathrm{L}}$ and $q_{\mathrm{m}}$ are determined from the intercept and slope of the linear plot of $C_{\mathrm{e}} / q_{\mathrm{e}}$ versus $\mathrm{C}_{\mathrm{e}}$ (Figs. 10a, b, 11a, b) and presented in Table 3. The essential feature of the Langmuir isotherm can be represented in terms of separation factor (dimensionless equilibrium parameter) $R_{\mathrm{L}}$ [53, 54], which can be expressed as follows:

$R_{\mathrm{L}}=\frac{1}{1+K_{\mathrm{L}} C_{\mathrm{o}}}$,

where $C_{0}$ is the initial concentrations of dyes, $K_{\mathrm{L}}$ is the constant related to the energy of adsorption (Langmuir Constant). RL value indicates the favorability nature of adsorption. If $R_{\mathrm{L}}>1$, the adsorption is unfavorable; if $R_{\mathrm{L}}=1$, the adsorption is linear; if $0<R_{\mathrm{L}}<1$, the adsorption is favorable; and if $R_{\mathrm{L}}=0$, then the adsorption is irreversible. From the data reported in Table 3 , the $R_{\mathrm{L}}$ is greater than 0 but less than 1 indicating the favorability of Langmuir isotherm for the adsorption of $\mathrm{RhB}$ and $\mathrm{C} 2 \mathrm{R}$. Similarly, comparing the $q_{\mathrm{m}}$ calculated (33.33 and $16.13 \mathrm{mg} / \mathrm{g})$ with the experimental $q_{\mathrm{m}}(35.7$ and $17.73 \mathrm{mg} /$ $\mathrm{g}$ ), respectively, for RhB and C2R on GG-g-poly(AMPSco-DMAPMAm)-8. This indicated the formation of a monolayer of $\mathrm{RhB}$ and $\mathrm{C} 2 \mathrm{R}$ on the surfaces of GG-g-poly (AMPS-co-DMAPMAm)-8.

The Freundlich adsorption isotherm is based on the assumption that encompasses the heterogeneity of the surface and the adsorption capacity related to the equilibrium concentration of the adsorbate. The Freundlich isotherm is commonly expressed as follows:

$\ln q_{\mathrm{e}}=\ln k_{\mathrm{f}}+\frac{1}{n} \ln C_{\mathrm{e}}$,

where $q_{\mathrm{e}}$ and $C_{\mathrm{e}}$ are the amount of dyes adsorbed $(\mathrm{mg} / \mathrm{g})$ and the equilibrium concentration of dyes $(\mathrm{mg} / \mathrm{L})$, respectively, $K_{\mathrm{f}}$ and $n$ are Freundlich adsorption isotherm constants that represent the adsorption capacity and the degree of nonlinearity between the dye concentration and the adsorption, respectively. The values of $K_{\mathrm{f}}$ and n were calculated from the intercept and slope of the plot between $\ln q_{\mathrm{e}}$ and $\ln C_{\mathrm{e}}$ (Figs. 10c, d, 11c, d) and are presented in Table 3. The value of $\mathrm{n}$ indicates whether the adsorption is favorable or otherwise. If it lies within the range of $1-10$, 

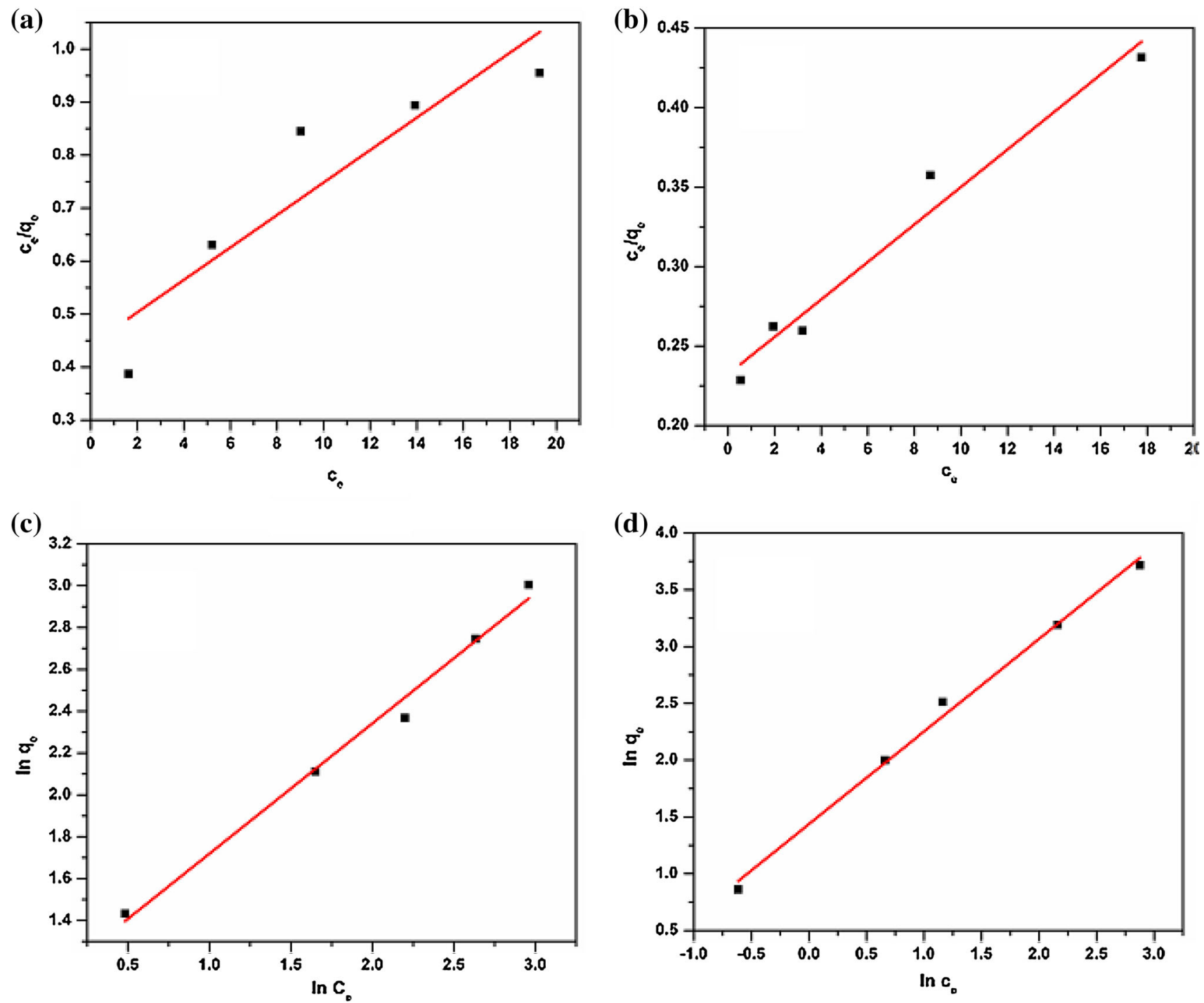

Fig. 10 Adsorption isotherms for rhodamine B dye. a Langmuir isotherm for GG-g-poly(AMPS-co-DMAPMAm)-8 gel, b Langmuir isotherm for GG-g-poly(AMPS-co-DMAPMAm)/MMT-3 composite

then the adsorption is considered favorable. In this case, the value of $n$ lies between 1.23 and 4.83 which shows a favorable adsorption. Similarly, the $R^{2}$ values for the adsorption of $\mathrm{RhB}$ and $\mathrm{C} 2 \mathrm{R}$ on GG-g-poly(AMPS-coDMAPMAm)/MMT-3 are 0.994 and 0.996, respectively, which are higher when compared with 0.989 and 0.990 , respectively, for RhB and C2R on GG-g-poly(AMPS-coDMAPMAm)-8. Hence, we can say that adsorption of RhB and C2R on GG-g-poly(AMPS-co-DMAPMAm)/MMT-3 base fits into the Freundlich model.

\section{Kinetic studies}

The adsorption capacity of $\mathrm{RhB}$ and $\mathrm{C} 2 \mathrm{R}$ dyes as a function of time by the adsorbents [GG-g-poly(AMPS-coDMAPMAm)-8 and GG-g-poly(AMPS-co-DMAPMAm)/

gel, c Freundlich isotherm for GG-g-poly(AMPS-co-DMAPMAm)-8 gel, and d Freundlich isotherm for GG-g-poly(AMPS-co-DMAPMAm)/MMT-3 composite

MMT-3] is shown in Fig. 9. The rate of adsorption of the dye uptake was little slow especially with respect to $\mathrm{C} 2 \mathrm{R}$ compared to $\mathrm{RhB}$ adsorption. The maximum adsorption observed in C2R was 17.72 and $16.99 \mathrm{mg} / \mathrm{g}$, respectively, for GG-g-poly(AMPS-co-DMAPMAm)-8 and GG-g-poly (AMPS-co-DMAPMAm)/MMT-3 after $12 \mathrm{~h}$. While higher adsorption capacity of 35.70 and $31.20 \mathrm{mg} / \mathrm{g}$ of $\mathrm{RhB}$ was recorded for GG-g-poly(AMPS-co-DMAPMAm)-8 and GG-g-poly(AMPS-co-DMAPMAm)/MMT-3, respectively, at $12 \mathrm{~h}$. The adsorption of $\mathrm{RhB}$ on different adsorbents has been reported [7, 49, 55, 56].

To investigate the mechanism of adsorption, the adsorption data obtained in this work were subjected to various kinetics models. The models employed in this work are Lagergren's pseudo-first-order [55, 57] and pseudosecond-order kinetic models. 

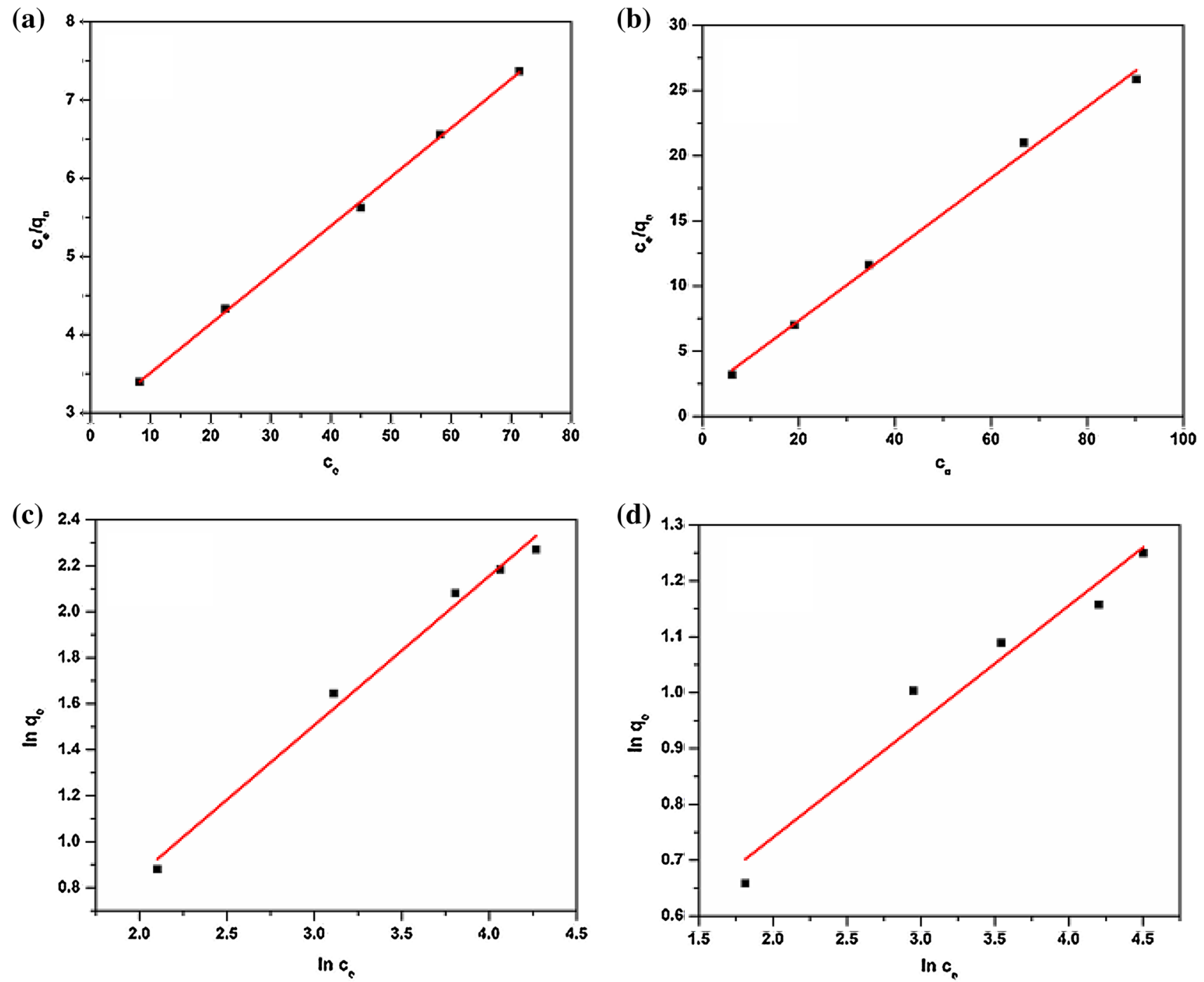

Fig. 11 Adsorption isotherms for chromotrope 2R dye. a Langmuir isotherm for GG-g-poly(AMPS-co-DMAPMAm)-8 gel, b Langmuir isotherm for GG-g-poly(AMPS-co-DMAPMAm)/MMT-3 composite

\section{Pseudo-first-order kinetics}

The Lagergren's pseudo-first-order kinetic model is based on assumption that the rate of adsorption of adsorbate with time is directly proportional to difference in equilibrium concentration and concentration with time and this can be represented as follows:

$\log \left(q_{\mathrm{e}}-q_{\mathrm{t}}\right)=\log q_{\mathrm{e}}-\frac{K_{1}}{2.303} t$,

where $q_{\mathrm{e}}$ and $q_{\mathrm{t}}$ are the amount of dyes adsorbed (mg/g) at equilibrium and at time $t$, respectively. $K_{1}$ is the rate constant $\left(\mathrm{h}^{-1}\right)$ for the pseudo-first-order kinetics and $t$ is the time (h) of adsorption. The value of $K_{1}$ and $R^{2}$ were calculated from the plot of $\log \left(q_{\mathrm{e}}-q_{\mathrm{t}}\right)$ versus $t$ and tabulated in Table 4 . The $q_{\mathrm{e}}$ cal for the first-order rate equation was

gel, c Freundlich isotherm for GG-g-poly(AMPS-co-DMAPMAm)-8 gel, and d Freundlich isotherm for GG-g-poly(AMPS-co-DMAPMAm)/MMT-3 composite

found to be in sharp disagreement with the $q_{\mathrm{e}}$ exp in all cases. Furthermore, the values of correlation coefficients are low, which is an indication of bad quality linearization. Hence, the adsorption cannot be said to be of first order. It has been suggested that the differences in experimental and theoretical $\mathrm{q}_{\mathrm{e}}$ values are that there is a time lag due to external resistance controlling at the beginning of the adsorption [57].

\section{Pseudo-second-order kinetics}

The kinetics studies of $\mathrm{RhB}$ and $\mathrm{C} 2 \mathrm{R}$ adsorption on the adsorbents was carried out using the initial dyes concentration of $100 \mathrm{mg} / \mathrm{L}$ in all cases. The pseudo-second-order rate expression of Ho and McKay [58] was adopted in this study and the best model that fit the adsorption was 
Table 3 Isotherm model parameters for the adsorption of rhodamine B and chromotrope 2R dyes on GG-g-poly(AMPS-co-DMAPMAm)-8 and GG-g-poly(AMPS-co-DMAPMAm)/MMT-3

\begin{tabular}{|c|c|c|c|c|c|}
\hline \multicolumn{2}{|l|}{ Dyes } & \multicolumn{2}{|l|}{$\mathrm{RhB}$} & \multicolumn{2}{|l|}{$\mathrm{C} 2 \mathrm{R}$} \\
\hline \multicolumn{2}{|l|}{ Adsorbent } & \multirow{2}{*}{$\begin{array}{l}\text { GG-g-poly(AMPS-co- } \\
\text { DMAPMAm)-8 } \\
10-100\end{array}$} & \multirow{2}{*}{$\begin{array}{l}\text { GG-g-poly(AMPS-co- } \\
\text { DMAPMAm)/MMT-3 } \\
10-100\end{array}$} & \multirow{2}{*}{$\begin{array}{l}\text { GG-g-poly(AMPS-co- } \\
\text { DMAPMAm)-8 } \\
\text { 10-100 }\end{array}$} & \multirow{2}{*}{$\begin{array}{l}\text { GG-g-poly(AMPS-co- } \\
\text { DMAPMAm)/MMT-3 } \\
10-100\end{array}$} \\
\hline & $\begin{array}{l}C_{\mathrm{o}} \\
(\mathrm{mg} / \mathrm{L})\end{array}$ & & & & \\
\hline \multirow{4}{*}{$\begin{array}{l}\text { Langmuir } \\
\text { model }\end{array}$} & $R_{\mathrm{L}}$ & $0.43-0.88$ & $0.797-0.975$ & $0.045-0.320$ & $0.19-0.165$ \\
\hline & $K_{\mathrm{L}}$ & 0.013 & 0.0026 & 0.212 & 0.509 \\
\hline & $\begin{array}{l}q_{\mathrm{m}} \\
(\mathrm{mg} / \\
\mathrm{g})\end{array}$ & 33.33 & 90.91 & 16.13 & 3.66 \\
\hline & $R^{2}$ & 0.841 & 0.969 & 0.999 & 0.996 \\
\hline \multirow{3}{*}{$\begin{array}{l}\text { Freundlich } \\
\text { model }\end{array}$} & $k_{\mathrm{f}}$ & 10.91 & 2.76 & 1.21 & 0.89 \\
\hline & $n$ & 1.61 & 1.23 & 1.54 & 4.83 \\
\hline & $R^{2}$ & 0.989 & 0.994 & 0.990 & 0.996 \\
\hline
\end{tabular}

$R^{2}$ linear regression correlation co-efficient

Table 4 Pseudo-first-order and pseudo-second-order kinetics model data for the adsorption of rhodamine B and chromotrope 2R dyes on GG-gpoly(AMPS-co-DMAPMAm)-8 and GG-g-poly(AMPS-co-DMAPMAm)/MMT-3

\begin{tabular}{|c|c|c|c|c|c|}
\hline \multicolumn{2}{|l|}{ Dye } & \multicolumn{2}{|l|}{$\mathrm{RhB}$} & \multicolumn{2}{|l|}{$\mathrm{C} 2 \mathrm{R}$} \\
\hline & & \multirow{2}{*}{$\begin{array}{l}\text { GG-g-poly(AMPS-co- } \\
\text { DMAPMAm)-8 } \\
35.70\end{array}$} & \multirow{2}{*}{$\begin{array}{l}\text { GG-g-poly(AMPS-co- } \\
\text { DMAPMAm)/MMT-3 } \\
31.92\end{array}$} & \multirow{2}{*}{$\begin{array}{l}\text { GG-g-poly(AMPS-co- } \\
\text { DMAPMAm)-8 } \\
17.73\end{array}$} & \multirow{2}{*}{$\begin{array}{l}\text { GG-g-poly(AMPS-co- } \\
\text { DMAPMAm)/MMT-3 } \\
17.56\end{array}$} \\
\hline & $\begin{array}{l}Q_{\mathrm{e} \exp }(\mathrm{mg} / \\
\mathrm{g})\end{array}$ & & & & \\
\hline \multirow[t]{3}{*}{$\begin{array}{l}\text { Pseudo-first-order } \\
\text { kinetic model }\end{array}$} & $\begin{array}{l}q_{\mathrm{e} \mathrm{cal}(\mathrm{mg} /} \\
\mathrm{g})\end{array}$ & 45.42 & 15.34 & 5.84 & 2.88 \\
\hline & $K_{1}\left(\mathrm{hr}^{-1}\right)$ & 0.15 & 0.198 & 0.32 & 0.124 \\
\hline & $R^{2}$ & 0.935 & 0.856 & 0.875 & 0.777 \\
\hline \multirow[t]{3}{*}{$\begin{array}{l}\text { Pseudo-second-order } \\
\text { kinetic model }\end{array}$} & $\begin{array}{l}q_{\text {ecal }}(\mathrm{mg} / \\
\mathrm{g}) .\end{array}$ & 37.04 & 34.48 & 18.18 & 17.24 \\
\hline & $\begin{array}{l}K_{2}(\mathrm{~g} / \\
\left.\mathrm{mghr}^{-1}\right)\end{array}$ & 0.016 & 0.028 & 0.016 & 0.01 \\
\hline & $R^{2}$ & 0.991 & 0.984 & 0.999 & 0.996 \\
\hline
\end{tabular}

$R^{2}$ linear regression correlation co-efficient

selected based on the values of the linear regression correlation co-efficient $\left(\mathrm{R}^{2}\right)$. The pseudo-second-order equation is given as follows:

$t / q=\frac{1}{k_{2} q_{\mathrm{e}}^{2}}+\frac{1}{q_{\mathrm{e}}} \times t$,

where $k_{2}$ is the adsorption rate constant for pseudo-secondorder kinetics $\left(\mathrm{gmg}^{-1} \mathrm{~h}^{-1}\right)$, and qe is the adsorption capacity calculated from pseudo-second-order kinetic model $\left(\mathrm{mgg}^{-1}\right), q_{\mathrm{e}}$ is the equilibrium adsorption $\left(\mathrm{mgg}^{-1}\right)$, and $t$ is the adsorption time (h). The linear form of the pseudo-second-order kinetic model is given in Fig. 12. The values of $k_{2}$, and $q_{\mathrm{e}}$ were calculated from the slope and intercept of the linear plot of $t / q$ vs $t$. The values of $R^{2}$ were higher than those in the pseudo-first-order model and they approach unity in all cases. Hence, the adsorption is of the second-order kinetics. In addition, the $\mathrm{q}_{\mathrm{e}}$ cal values are in agreement with the $q_{\mathrm{e}}$ exp. Therefore, the experimental results support the assumption behind the model that the rate-limiting step in the adsorption of dyes are chemisorptions involving valence forces through the exchange of electrons between adsorbent and dyes [7]. A similar finding was reported in the literature [59, 60].

\section{Desorption studies}

The re-usability of GG-g-poly(AMPS-co-DMAPMAm)-8 gel and GG-g-poly(AMPS-co-DMAPMAm)/MMT-3 

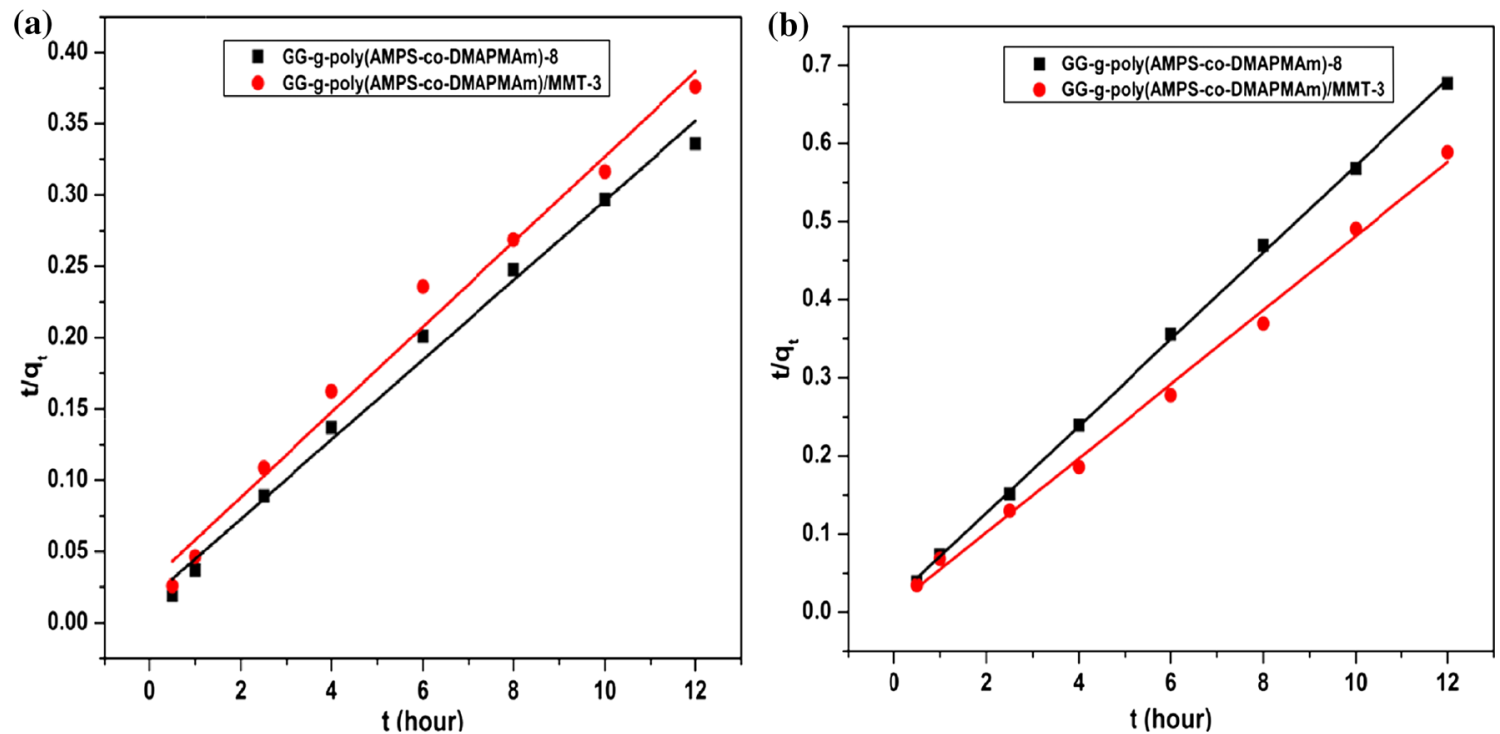

Fig. 12 Pseudo-second-order kinetics for the adsorption of a rhodamine B and b Chromotrope 2R Dyes on GG-g-poly(AMPS-co-DMAPMAm)8 and GG-g-poly(AMPS-co-DMAPMAm)/MMT-3

Table 5 Desorption capacity (\%) of GG-g-poly(AMPS-coDMAPMAm)-8 and GG-g-poly (AMPS-co-DMAPMAm)/ MMT-3 for RhB and C2R under $\mathrm{pH} 1.2$ and $\mathrm{pH} 13.0$

\begin{tabular}{|c|c|c|c|c|}
\hline \multirow[t]{3}{*}{$\mathrm{PH}$} & \multicolumn{4}{|c|}{ Desorption $(\%)$} \\
\hline & \multicolumn{2}{|c|}{ GG-g-poly(AMPS-co-DMAPMAm)-8 } & \multicolumn{2}{|c|}{ GG-g-poly(AMPS-co-DMAPMAm)/MMT-3 } \\
\hline & $\mathrm{RhB}$ & $\mathrm{C} 2 \mathrm{R}$ & $\mathrm{RhB}$ & $\mathrm{C} 2 \mathrm{R}$ \\
\hline \multicolumn{5}{|c|}{ First cycle } \\
\hline 1.2 & 91.57 & 48.50 & 94.25 & 48.34 \\
\hline 13.0 & 83.18 & 41.85 & 91.69 & 43.92 \\
\hline \multicolumn{5}{|c|}{ Second cycle } \\
\hline 1.2 & 89.23 & 42.23 & 83.17 & 44.03 \\
\hline 13.0 & 74.12 & 38.11 & 64.98 & 39.62 \\
\hline
\end{tabular}

Table 6 Comparison of adsorption capacity of dyes onto different adsorbents

\begin{tabular}{|c|c|c|c|}
\hline Adsorbate & Adsorbent & $Q_{\mathrm{e}}(\mathrm{mg} / \mathrm{g})$ & References \\
\hline $\mathrm{RhB}$ & GG-g-poly(AMPS-co-DMAPMAm)-8 & 35.70 & Present work \\
\hline $\mathrm{RhB}$ & GG-g-poly(AMPS-co-DMAPMAm)/MMT-3 & 31.92 & Present work \\
\hline $\mathrm{C} 2 \mathrm{R}$ & GG-g-poly(AMPS-co-DMAPMAm)-8 & 17.73 & Present work \\
\hline $\mathrm{C} 2 \mathrm{R}$ & GG-g-poly(AMPS-co-DMAPMAm)/MMT-3 & 17.56 & Present work \\
\hline $\mathrm{RhB}$ & Acid activated mango leaf powder & 3.85 & [7] \\
\hline $\mathrm{RhB}$ & Palm shell-based activated carbon & 2.92 & [49] \\
\hline $\mathrm{RhB}$ & Coffee powder & 4.018 & {$[59]$} \\
\hline Methyl orange & Gellan gum-graft-poly(DMAEMA) & 25.8 & {$[31]$} \\
\hline $\mathrm{C} 2 \mathrm{R}$ & Carbons modified with lanthanum & 164 & {$[60]$} \\
\hline Methylene blue & Poly(acrylic acid-co-acrylamide) & 1313 & {$[61]$} \\
\hline Methylene blue and Direct blue & Polyacrylamide/chitosan & 6.744 & {$[63]$} \\
\hline $\mathrm{RhB}$ & Rice husk activated carbon & 275.2 & {$[59]$} \\
\hline Crystal violet & Car/poly(AAm-co-Na-AA)-MMT & 46.15 & {$[64]$} \\
\hline Crystal violet & CarAlg/MMT & 88.8 & [23] \\
\hline
\end{tabular}


suspending about $15 \mathrm{mg}$ of the adsorbent in $25 \mathrm{~mL}$ of solution ( $\mathrm{pH} 1.2$ and $\mathrm{pH} 13.0$ ) allowed to stand for $8 \mathrm{~h}$ at room temperature. The solutions were filtered and diluted appropriately and the absorbance of the desorbed $\mathrm{RhB}$ and $\mathrm{C} 2 \mathrm{R}$ were measured using $\mathrm{UV}-\mathrm{V}$ is spectrophotometer. The amounts of the two dyes were calculated using Eq. (6). The percentage of desorption for the dyes was calculated using the following equation [61]:

Desorption $(\%)=\frac{\text { Amount of dye desorbed }}{\text { Amount of dye adsorbed }} \times 100$.

It was clear from Table 5 that $\mathrm{RhB}$ can be efficiently removed by regenerating the adsorbent at least twice under $\mathrm{pH} 1.2$ and 13.0, whereas desorption of $\mathrm{C} 2 \mathrm{R}$ under the same conditions is low. In all cases, the \% desorption is high at $\mathrm{pH}$ 1.2 and this could be attributed to the reaction between $\mathrm{H}^{+}$ and a lone pair of electrons in both the secondary amine groups of the adsorbent and the tertiary nitrogen of $\mathrm{RhB}$. Hence, more of RhB will go into solution [62].

The adsorption capacity of GG-g-poly(AMPS-coDMAPMAm)-8 gel and GG-g-poly(AMPS-co-DMAPMAm)/MMT-3 on RhB and C2R is compared with other previously developed adsorbents [7, 23, 31, 49, 59-61, 63, 64] towards different adsorbates and presented in Table 6.

\section{Conclusion}

In this work, an amphoteric terpolymer consisting of gel GG, AMPS, and DMAPMAm, and its clay composite containing MMT have successfully been synthesized and studied. The GG-g-poly(AMPS-co-DMAPMAm)-8 gel showed maximum swelling at $\mathrm{pH}$ of 9.0 and GG-g-poly (AMPS-co-DMAPMAm)/MMT-3 composite shows maximum swelling at neutral $\mathrm{pH}$. The adsorption of $\mathrm{RhB}$ and $\mathrm{C} 2 \mathrm{R}$ dyes on the gels/composite is higher for $\mathrm{RhB}$ compared to $\mathrm{C} 2 \mathrm{R}$. The adsorption kinetic studies revealed a second-order adsorption process. Furthermore, adsorption of $\mathrm{RhB}$ and $\mathrm{C} 2 \mathrm{R}$ on to GG-g-poly(AMPS-co-DMAPMAm)-8 and GG-g-poly(AMPS-co-DMAPMAm)/MMT-3 was found to best fit into the Langmuir and Freundlich models, respectively.

Acknowledgements One of the authors SAZ thanks the Government of India for providing the scholarship under the Indian Council for Cultural Relations (ICCR) and Usmanu Danfodiyo University, Sokoto, Nigeria for the study leave.

Open Access This article is distributed under the terms of the Creative Commons Attribution 4.0 International License (http://crea tivecommons.org/licenses/by/4.0/), which permits unrestricted use, distribution, and reproduction in any medium, provided you give appropriate credit to the original author(s) and the source, provide a link to the Creative Commons license, and indicate if changes were made.

\section{References}

1. Wang L, Wang A (2007) Adsorption characteristics of Congo Red onto the chitosan/montmorillonite nanocomposite. J Hazard Mater 147:979-985

2. Luo P, Zhao Y, Zhang B, Liu J, Yang Y, Liu J (2010) Study on the adsorption of Neutral Red from aqueous solution onto halloysite nanotubes. Water Res 44:1489-1497

3. Jiang R, Fu Y, Zhu H, Yao J, Xiao L (2012) Removal of methyl orange from aqueous solutions by magnetic maghemite/chitosan nanocomposite films: adsorption kinetics and equilibrium. J Appl Polym Sci 125:540-549

4. Ganesan V, Girija EK (2015) Investigations on textile dye adsorption onto hydroxyapatite-alginate nanocomposite prepared by a modified method. Cellul Chem Technol 49:87-91

5. Gupta SK, Nayunigari MK, Misra R, Ansari FA, Dionysiou DD, Maity A, Bux F (2016) Synthesis and performance evaluation of a new polymeric composite for the treatment of textile wastewater. Ind Eng Chem Res 55:13-20

6. Chemwatch, Chromotrope 2R (2010) Material safety data sheet sc-214716. Available at:http://www.chemwatch.net/solutions/ msds/chromotrope2r. Accessed on 12 May 2016

7. Khan TA, Sharma S, Ali I (2011) Adsorption of rhodamine B dye from aqueous solution onto acid activated mango (Magnifera indica) leaf powder: equilibrium, kinetic and thermodynamic studies. J Toxicol Environ Health Sci 3:286-297

8. Sebastian S, Mayadevi S, Beevi BS, Mandal S (2014) Layered clay-alginate composites for the adsorption of anionic dyes: a biocompatible solution for water/wastewater treatment. J Water Res Prot 6:177-184

9. Abd El-Latif MM, Ibrahim AM, El-Kady MF (2010) Adsorption equilibrium, kinetics and thermodynamics of methylene blue from aqueous solutions using biopolymer oak sawdust composite. J Am Sci 6:267-283

10. El Haddad M, Mamouni R, Saffaj N, Lazar S (2012) Adsorptive removal of basic dye rhodamine $\mathrm{B}$ from aqueous media onto animal bone meal as new low cost adsorbent. Glob J Hum Soc Sci Geog Environ Geo-Sci 12:19-29

11. Patil MR, Shrivastava VS (2015) Adsorption removal of carcinogenic acid violet19 dye from aqueous solution by polyaniline- $\mathrm{Fe}_{2} \mathrm{O}_{3}$ magnetic nano-composite. J Mater Environ Sci 6:11-21

12. Casey LS, Wilson LD (2015) Investigation of Chitosan-pva composite films and their adsorption properties. J Geosci Environ Prot 3:78-84

13. Datskevich EV, Prikhod'ko RV, Stolyarova IV, Lozovskii AV, Goncharuk VV (2010) Poly(acrylamide-sepiolite) composite hydrogels: preparation, swelling and dye adsorption properties. Russian J Appl Chem 83(10):1785-1793

14. Santos SCR, Boaventura RAR (2016) Adsorption of cationic and anionic azo dyes on sepiolite clay: Equilibrium and kinetic studies in batch model. J Environ Chem Eng 4:1473-1483

15. Mahida VP, Patel MP (2016) Superabsorbent amphoteric nanohydrogels: synthesis, characterization and dyes adsorption studies. Chin Chem Lett 27:471-474

16. Maity J, Ray SK (2016) Enhanced adsorption of Cr(VI) from water by guar gum based composite hydrogels. Int $\mathrm{J}$ Biol Macromol 89:246-255

17. Robati D, Mirza B, Ghazisaeidi R, Rajabi M, Moradi O, Tyagi I, Agarwal S, Gupta VK (2016) Adsorption behavior of methylene blue dye on nanocomposite multi-walled carbon nanotube functionalized thiol (MWCNT-SH) as new adsorbent. J Mol Liq 216:830-835

18. Postai DL, Demarchi CA, Zanatta F, Melo DCC, Rodrigues CA (2016) Adsorption of rhodamine B and methylene blue dyes 
using waste of seeds of Aleurites moluccana, a low cost adsorbent. Alexandria Eng J 55:1713-1723

19. Shabbir M, Rather LJ, Bukhari MN, Shahid M, Khan MA, Mohammad F (2016) An eco-friendly dyeing of woolen yarn by Terminalia chebula extract with evaluations of kinetic and adsorption characteristics. J Adv Res 7:473-482

20. Reynel-Avila HE, Mendoza-Castillo DI, Bonilla-Petriciolet A (2016) Relevance of anionic dye properties on water decolorization performance using bone char: adsorption kinetics, isotherms and breakthrough curves. J Mol Liq 219:425-434

21. Sharma K, Kaith BS, Kumar V, Kalia S, Kumar V, Swart HC (2014) Water retention and dye adsorption behaviour of Gg-clpoly(acrylic acid-aniline) based conductive hydrogels. Geoderma 232-234:45-55

22. Mahdavinia GR, Massoumi B, Jalili K, Kiani G (2012) Effect of sodium montmorillonite nanoclay on the water absorbency and cationic dye removal of carrageenan-based nanocomposite superabsorbents. J Polym Res 19(9):9947

23. Mahdavinia GR, Aghaie H, Sheykhloie H, Vardini MT, Etemadi H (2013) Synthesis of CarAlg/MMt nanocomposite hydrogels and adsorption of cationic crystal violet. Carbohydr Polym 98 (1):358-365

24. Mahdavinia GR, Baghban A, Zorofi S, Massoudi A (2014) Kappa-carrageenan biopolymer-based nanocomposite hydrogel and adsorption of methylene blue cationic dye from water. J Mater Environ Sci 5(2):330-337

25. Auta M, Hameed BH (2014) Chitosan-clay composite as highly effective and low-cost adsorbent for batch and fixed-bed adsorption of methylene blue. Chem Eng J 237:352-361

26. Sharma R, Kalia S, Kaith BS, Pathania D, Kumar A, Thakur P (2015) Guaran-based biodegradable and conducting interpenetrating polymer network composite hydrogels for adsorptive removal of methylene blue dye. Polym Degrad Stab 122:52-65

27. Nie X, Adalati A, Du J, Liu H, Xu S, Wang J (2014) Preparation of amphoteric nanocomposite hydrogels based on exfoliation of montmorillonite via in-situ intercalative polymerization of hydrophilic cationic and anionic monomers. Appl Clay Sci 9798:132-137

28. Atta S, Khaliq S, Islam A, Javeria I, Jamil T, Athar MM, Shafiq MI, Ghaffar A (2015) Injectable biopolymer based hydrogels for drug delivery applications. Int J Biol Macromol 80:240-245

29. Mohsen M, Maziad NA, Gomaa E, Aly EH, Mohammed R (2015) Characterization of some hydrogels used in water purification: correlation of swelling and free-volume properties. Open J Org Polym Mater 5:79-88

30. Chen X (2015) Modeling of experimental adsorption isotherm data. Information 6:14-22

31. Karthika JS, Vishalakshi B (2015) Novel stimuli responsive gellan gum-graft-poly(DMAEMA) hydrogel as adsorbent for anionic dye. Int J Biol Macromol 81:544-655

32. Zhang S, Guan Y, Fu GQ, Chen BY, Peng F, Yao C, Sun R (2014) Organic/inorganic superabsorbent hydrogels based on xylan and montmorillonite. J Nanomater 2014:1-11

33. Wilpiszewska K, Spychaj T, Pa'zdzioch W (2016) Carboxymethyl starch/montmorillonite composite microparticles: Properties and controlled release of isoproturon. Carbohydr Polym 136:101-106

34. Guinier A (1994) Imperfect crystals and amorphous bodies. Freeman \& Co., San Francisco

35. Verma SK, Pandey VS, Behari MYK (2015) Gellan gum-g-Nvinyl-2-pyrrolidone: synthesis, swelling, metal ion uptake and flocculation behavior. Int J Biol Macromol 72:1292-1300

36. Speakman AA (2013) Introduction to X-ray powder diffraction data analysis. Center for Materials Science and Engineering at MIT, USA
37. Binitha N, Suraja V, Yaakob Z, Sugunan S (2011) Synthesis of polyaniline-montmorillonite nanocomposites using $\mathrm{H}_{2} \mathrm{O}_{2}$ as the oxidant. Sains Malaysiana 40:215-219

38. Mahdavinia GR, Pourjavadi A, Hosseinzadeh H, Zohourian MJ (2004) Modified chitosan 4. Superabsorbent hydrogels from poly (acrylic acid-co-acrylamide) grafted chitosan with salt-and $\mathrm{pH}-$ responsiveness properties. Eur Polym J 40(7):1399-1407

39. Mahdavinia GR, Rahmani Z, Karami S, Pourjavadi A (2014) Magnetic/pH-sensitive $\kappa$-carrageenan/sodium alginate hydrogel nanocomposite beads: preparation, swelling behavior, and drug delivery. J Biomater Sci Polym Ed 25(17):1891-1906

40. Wang B, Xu X, Wang Z, Cheng S, Zhang X, Zhou R (2008) Synthesis and properties of $\mathrm{pH}$ and temperature sensitive $\mathrm{P}$ (NIPAAm-co-DMAEMA) hydrogels. Colloids Surf B 64:34-41

41. Shukla NB, Rattan S, Madras G (2012) Swelling and dye-adsorption characteristics of amphoteric superabsorbent polymer. Ind Eng Chem Res 51:14941-14948

42. Murthy PSK, Mohan YM, Sreeramulu J, Raju KM (2006) SemiIPNs of starch and poly(acrylamide-co-sodium methacrylate): preparation, swelling and diffusion characteristics evaluation. React Funct Polym 66:1482-1493

43. Mahdavinia GR, Mosallanezhad A (2016) Facile and green rout to prepare magnetic and chitosan-crosslinked $\kappa$-carrageenan bionanocomposites for removal of methylene blue. J Water Process Eng 10:143-155

44. Katime I, Mendizábal E (2010) Swelling properties of new hydrogels based on the dimethyl amino ethyl acrylate methyl chloride quaternary salt with acrylic acid and 2-methylene butane-1,4-dioic acid monomers in aqueous solutions. Mater Sci Appl 1:162-167

45. Hiremath JN, Vishalakshi B (2012) Effects of crosslinking on swelling behavior of IPN hydrogels of guar gum and polyacrylamide. Der Pharma Chemica 4:946-955

46. Ganji F, Vasheghani-Farahani S, Vasheghani-Farahani E (2010) Theoretical description of hydrogel swelling: a review. Iranian Polym J 19:375-398

47. Mithun U, Vishalakshi B (2014) Swelling kinetics of a pH-sensitive polyelectrolyte complex of polyacrylamide-g-alginate and chitosan. Int J ChemTech Res 6:3579-3588

48. Shukla NB, Madras G (2013) Adsorption of anionic dyes on a reversibly swelling cationic superabsorbent polymer. J Appl Polym Sci 127(3):2251-2258

49. Mohammadi M, Hassani AJ, Mohamed A, Najafpour GD (2010) Removal of rhodamine B from aqueous solution using palm shellbased activated carbon: adsorption and kinetic studies. J Chem Eng Data 55:5777-5785

50. Dada AO, Olalekan AP, Olatunya AO, Dada O (2012) Langmuir, Freundlich, Temkin and Dubinin-Radushkevich isotherms studies of equilibrium sorption of $\mathrm{Zn}^{2+}$ unto phosphoric acid modified rice. IOSR J Appl Chem 3:38-45

51. Bas N, Yakar A, Bayramgil NP (2014) Removal of cobalt ions from aqueous solutions by using poly $(\mathrm{N}, \mathrm{N}$-dimethylaminopropyl methacrylamide/itaconic acid) hydrogels. J Appl Polym Sci 131:1-12

52. Zhao Z, Wang X, Zhao C, Zhu X, Du S (2010) Adsorption and desorption of antimony acetate on sodium montmorillonite. J Colloid Interface Sci 345:154-159

53. Kruśic MK, Milosavljevic N, Debeljković A, Üzüm ÖB, Karadaǵ $\mathrm{E}$ (2012) Removal of $\mathrm{Pb}^{2+}$ ions from water by poly(acrylamideco-sodium methacrylate) hydrogels. Water Air Soil Pollut 223:4355-4368

54. Garba ZN, Bello I, Galadima A, Lawal AY (2016) Optimization of adsorption conditions using central composite design for the removal of copper (II) and lead (II) by defatted papaya seed. Karbala Int J Modern Sci 2:20-28 
55. Al-Rashed SM, Al-Gaid AA (2012) Kinetics and thermodynamic studies on the adsorption behavior of rhodamine B dye on Duolite C-20 resin. J Saudi Chem Soc 16:209-215

56. Shen K, Gondal MA (2013) Removal of hazardous Rhodamine dye from water by adsorption on to exhausted coffee ground. J Saudi Chem Soc. doi:10.1016/j.jscs.2013.11.005 (article in press)

57. Hu X, Wang J, Liua Y, Li X, Zenga G, Baoc Z, Zenga X, Chena A, Longa F (2011) Adsorption of chromium (VI) by ethylenediamine-modified cross-linked magnetic chitosan resin: Isotherms, kinetics and thermodynamics. J Hazard Mater 185:306-314

58. Ho YS, McKAY G (1998) A comparison of chemisorptions kinetics models applied to pollutant removal of various sorbents. Trans IchemE 76(4):332-340

59. Ding L, Zou B, Gao W, Liu Q, Wang Z, Guo Y, Wang X, Liu Y (2014) Adsorption of rhodamine-B from aqueous solution using treated rice husk-based activated carbon. Colloids Surf A 446:1-7

60. Goscianska J, Ptaszkowska M, Pietrzak R (2015) Equilibrium and kinetic studies of chromotrope $2 \mathrm{R}$ adsorption onto ordered mesoporous carbons modified with lanthanum. Chem Eng J 270:140-149

61. Mekewi MA, Madkour TK, Darwish AS, Hashish YM (2015) Does poly(acrylic acid-co-acrylamide) hydrogel be the pluperfet choiceness in treatment of dyeing wastewater? "From simple copolymer to gigantic aqua-waste remover". J Ind Eng Chem 30:359-371

62. Song W, Gao B, Xu X, Xing L, Han S, Duan P, Song W, Jia R (2016) Adsorption-desorption behavior of magnetic amine/ $/ \mathrm{Fe}_{3} \mathrm{O}_{4}$ functionalized biopolymer resin towards anionic dyes from wastewater. Bioresour Technol 210:123-130

63. Dragan ES, Perju MM, Dinu MV (2012) Preparation and characterization of IPN composite hydrogels based on polyacrylamide and chitosan and their interactions with ionic dyes. Carbohydr Polym 88:270-281

64. Mahdavinia GR, Massoumi B, Jalili K, Kiani G (2012) Effect of sodium montmorillonite nanoclay on the water absorbency and cationic dye removal of carrageenan-based nanocomposite superabsorbents. J Polym Res 19(9):9947 